\title{
DNA-Encoded Library-Derived DDR1 Inhibitor Prevents Fibrosis and Renal Function Loss in a Genetic Mouse Model of Alport Syndrome
} \author{
Hans Richter, ${ }^{\dagger,+}$ Alexander L. Satz,,$^{*,+,}{ }^{\dagger}$ Marc Bedoucha, ${ }^{\dagger}$ Bernd Buettelmann, ${ }^{\dagger}$ Ann C. Petersen, ${ }^{\dagger}$
} Anja Harmeier ${ }^{\dagger}$ Ricardo Hermosilla, ${ }^{\dagger}$ Remo Hochstrasser, ${ }^{\dagger}$ Dominique Burger, ${ }^{\dagger}$ Bernard Gsell, ${ }^{\dagger}$ Rodolfo Gasser, ${ }^{\dagger}$ Sylwia Huber, ${ }^{\dagger}$ Melanie N. Hug, ${ }^{\dagger}$ Buelent Kocer, ${ }^{\dagger}$ Bernd Kuhn, ${ }^{\dagger}$ Martin Ritter, ${ }^{\dagger}$ Markus G. Rudolph, ${ }^{\dagger}$ Franziska Weibel, ${ }^{\dagger, \text { II }}$ Judith Molina-David, ${ }^{\ddagger,}$ Jin-Ju Kim, ${ }^{\ddagger, \delta}$ Javier Varona Santos,, , \& Martine Stihle, ${ }^{\dagger}$ Guy J. Georges, ${ }^{\#}$ R. Daniel Bonfil, ${ }^{\nabla}$ Rafael Fridman, ${ }^{\bigcirc}$ Sabine Uhles, ${ }^{\dagger}$ Solange Moll, ${ }^{\perp}$ Christian Faul,,$\|$ Alessia Fornoni, ${ }^{*} *$ and Marco Prunotto*, $*, \wedge$

${ }^{\dagger}$ Roche Pharma Research and Early Development, Roche Innovation Center, Basel 4070, Switzerland

${ }^{\ddagger}$ Katz Family Division of Nephrology and Hypertension, University of Miami Miller School of Medicine, Miami, Florida 33136, United States

${ }^{\S}$ Peggy and Harold Katz Family Drug Discovery Center, University of Miami Miller School of Medicine, Miami, Florida 33136, United States

"University of Alabama at Birmingham, Birmingham, Alabama 35294, United States

${ }^{\perp}$ University Hospital of Geneva, 1205 Geneva, Switzerland

${ }^{\#}$ Roche Pharma Research and Early Development, Roche Innovation Center, Munich 82377, Germany

${ }^{\nabla}$ Department of Pathology, College of Medical Sciences, Nova Southeastern University, Fort Lauderdale, Florida 33328, United States

ODepartment of Pathology, Wayne State University, Detroit, Michigan 48202, United States

Office of Innovation, Immunology, Infectious Diseases \& Ophthalmology (I2O), Roche and Genentech Late Stage Development, Basel 4070, Switzerland

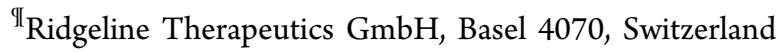

Supporting Information

DEL-derived selective and potent in vivo inhibitors of DDR1 autophosphorylation
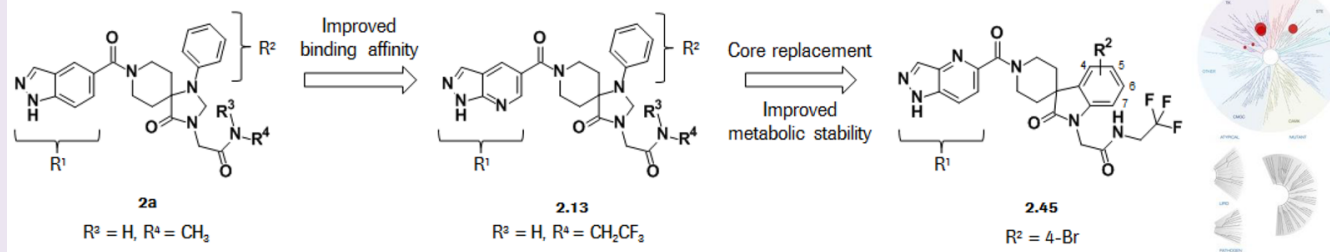

ABSTRACT: The importance of Discoidin Domain Receptor 1 (DDR1) in renal fibrosis has been shown via gene knockout and use of antisense oligonucleotides; however, these techniques act via a reduction of DDR1 protein, while we prove the therapeutic potential of inhibiting DDR1 phosphorylation with a small molecule. To date, efforts to generate a selective smallmolecule to specifically modulate the activity of DDR1 in an in vivo model have been unsuccessful. We performed parallel DNA encoded library screens against DDR1 and DDR2, and discovered a chemical series that is highly selective for DDR1 over DDR2. Structure-guided optimization efforts yielded the potent DDR1 inhibitor 2.45, which possesses excellent kinome selectivity (including 64-fold selectivity over DDR2 in a biochemical assay), a clean in vitro safety profile, and favorable pharmacokinetic and physicochemical properties. As desired, compound 2.45 modulates DDR1 phosphorylation in vitro as well as prevents collagen-induced activation of renal epithelial cells expressing DDR1. Compound 2.45 preserves renal function and reduces tissue damage in Col4a $3^{-/-}$mice (the preclinical mouse model of Alport syndrome) when employing a therapeutic dosing regime, indicating the real therapeutic value of selectively inhibiting DDR1 phosphorylation in vivo. Our results may have continued... 
Table 1. Eleven Prioritized Clusters Following Analysis of DNA Encoded Library Screening Data

\begin{tabular}{|c|c|c|c|c|c|}
\hline Exemplar ID & $\begin{array}{c}\text { DDR1 } \\
\text { binding } \\
\text { compeition } \\
\left(\mathrm{IC}_{50} \mu \mathrm{M}\right)\end{array}$ & $\begin{array}{c}\text { Cluster } \\
\text { Size }^{b}\end{array}$ & Exemplar & $\begin{array}{c}\text { DDR1 } \\
\text { binding } \\
\text { competition } \\
\left(\mathrm{IC}_{50} \mu \mathrm{M}\right) \\
\end{array}$ & $\begin{array}{c}\text { Cluster } \\
\text { Size }\end{array}$ \\
\hline 1a & 0.40 & 26 & $7 a$ & 3.6 & 3 \\
\hline $2 a$ & 1.5 & 19 & $8 a$ & 2.0 & 2 \\
\hline $3 a$ & 1.8 & 16 & $9 a$ & 1.2 & 1 \\
\hline $4 a$ & 2.7 & 15 & $10 \mathrm{a}$ & 3.9 & 1 \\
\hline $5 a$ & 0.12 & 7 & 11a & 1.4 & 1 \\
\hline $6 a$ & 2.6 & 6 & & & \\
\hline
\end{tabular}

${ }^{a}$ For brevity, a single exemplar compound for each cluster is provided above; see Table S1 for a list of all investigated exemplars derived from clusters $1-11 .{ }^{b}$ Numeric count of library members contained within each cluster (with enrichment over baseline $>10$-fold). A list of all library members contained within each cluster is provided in Table S3.

wider significance as $\mathrm{Col}_{4} 3^{-/-}$mice also represent a model for chronic kidney disease, a disease which affects $10 \%$ of the global population.

$\mathrm{F}$ ibrogenesis is a naturally occurring process that in homeostatic conditions promotes tissue repair leading to wound closure, and it is therefore essential to prevent infections. However, in pathologic circumstances, fibrosis evolves into an uncontrolled process characterized by the progressive accumulation of extracellular matrix (ECM), mainly collagens, that ultimately disrupts normal organ architecture and leads to organ function loss. ${ }^{1-3}$ Fibrosis impacts several organs (e.g., liver, lung, heart, and skin), and in the progression of chronic kidney disease (CKD) is the common pathway to renal failure., ${ }^{4,5}$ Unfortunately, though fibrosis is a recognized driver of CKD progression, nephrologists lack antifibrotic specific drugs. Though published more than 20 years ago, blockers of the renin angiotensin system remain the only therapeutic option available to treat CKD patients. ${ }^{6}$

Among the biological targets currently being investigated for the development of novel antifibrotic medications, collagen and its receptors have been extensively explored due to their tight relation to disease progression. Among those receptors, an impressive series of preclinical studies have highlighted a major role of integrins ${ }^{7}$ and Discoidin Domain Receptor(DDR) 1 [reviewed here: refs 8-10] in the pathogenesis of renal fibrosis. DDR1, initially discovered in the early 1990s, represents a very attractive target as it is the only tyrosine kinase collagen receptor. ${ }^{11}$ Upon collagen binding, DDR1 undergoes tyrosine autophosphorylation with distinctive and delayed activation kinetics, which activates genetic and cellular pathways that regulate a variety of cell-collagen interactions. ${ }^{12}$ Inhibiting the autophosphorylation of DDR1 therefore holds the promise of profound downstream effects. Additionally, in humans, single nucleotide polymorphisms of Ddrl are associated with susceptibility and disease progression of childhood nephropathy, ${ }^{13}$ further strengthening the role of DDR1 in human renal diseases. Therefore, it is hypothesized that the pharmacological targeting of DDR1 in nephropathies with inflammatory responses and fibrosis would be beneficial.

DDR1 has been explored extensively in preclinical models of $\mathrm{CKD}$ relying uniquely on gene knockout $(\mathrm{KO})$ and use of antisense oligonucleotides (ASO), in hypertension-induced kidney disease, ${ }^{14}$ obstructive nephropathy, ${ }^{15}$ and crescentic glomerulonephritis. ${ }^{14-18}$ However, the above techniques, acting via a reduction of DDR1 protein, have only very limited translation potential. Knockout mouse models mimic a prophylactic regime not applicable in CKD as most patients in a clinical setting suffer from substantial loss of kidney function prior to treatment, and ASOs are prevailingly cleared by the liver and kidneys (a nonpreferred clinical scenario in renally impaired patients).

To date, efforts to identify an appropriate chemical probe to modulate the activity of DDR1 in an in vivo model have been unsuccessful, largely because investigated molecules lack selectivity across the kinome. ${ }^{19-21}$ Although an unselective profile is tolerable in a preclinical study, it is an unacceptable safety risk in a longer clinical study for a chronic treatment 


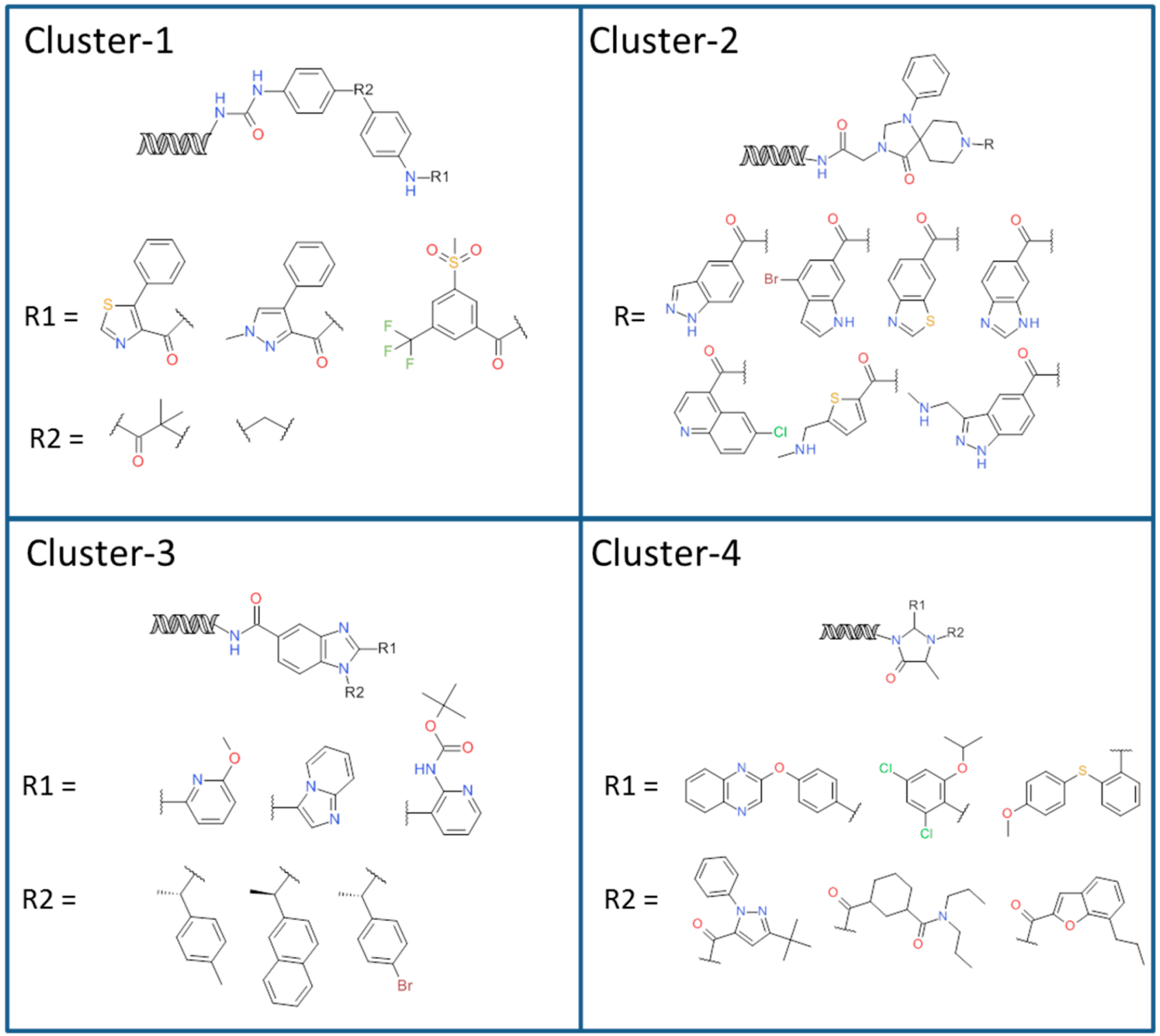

Figure 1. Structural diversity of enriched library members within a cluster is illustrated by selected examples taken from clusters $1-4$. A list of all enriched library molecules is provided in Table S3.

indication such as $\mathrm{CKD}$. The challenge in creating the required selective ATP-competitive DDR1 inhibitor resides in the high homology existing in the kinase domains bound by such molecules. ${ }^{22}$ We additionally desire molecules selective for DDR1 over its close analogue DDR2, as studies suggest that a loss of DDR2 may promote chronic liver fibrosis. ${ }^{23}$

In the present work, we attempt to identify novel and selective inhibitors of DDR1 phosphorylation. In particular, we employ parallel DNA encoded library (DEL) screens against DDR1 and its close analogue DDR2 to discover numerous distinct chemical series, including one series that is $>100$-fold selective for DDR1 over DDR2. We improve the potency of the selective chemical series through structure-guided optimization leading to compound 2.45, a bioavailable DDR1 selective inhibitor. The obtained lead compound was characterized in vitro and dosed in vivo. We assessed the efficacy of $\mathbf{2 . 4 5}$ in Col4a $3^{-/^{-}}$mice, a mouse model phenocopying Alport syndrome, ${ }^{24}$ a hereditary rare disease which closely resembles $\mathrm{CKD}$ and is caused by mutations in collagen type IV. ${ }^{24,25}$ Our in vivo results (employing a therapeutic regime) prove the therapeutic value of selectively inhibiting DDR1 phosphorylation, with improvement of renal function comparable to previously described gene knockdown experiments. ${ }^{25,26}$

\section{RESULTS AND DISCUSSION}

Parallel DEL Screens Identify DDR1 Active Chemical Clusters. We performed several DEL screens, resulting in the discovery of 11 structurally distinct chemical clusters with confirmed activity against DDR1 (Table 1). Exemplar compounds from each cluster were synthesized, resulting in the discovery of 16 confirmed active molecules (Table S1). The synthesized compounds reside in drug-like property space and possess clear vectors for further optimization. Our screening efforts employed two different library pools: pool 1 contained libraries $1-10$ (total numeric size of $\sim 83$ billion smallmolecules), and pool 2 contained libraries $1-16$ ( $\sim 85$ billion small-molecules). Generic library schemas are provided in Table S2. Note that each library possesses a unique identifier in its DNA barcode, allowing libraries to be pooled together and screened in a single pot. ${ }^{27}$ Some enriched clusters did not result 
in active compounds and are not discussed herein; a detailed analysis of DEL screening confirmation rates is provided by Eidam and Satz. ${ }^{27}$ Eleven clusters are derived from five different libraries (Table S1); thus, the remaining 11 screened libraries failed to contribute useful chemical matter.

The structural similarities and differences between library members within each cluster provided a useful starting point for medicinal chemistry efforts; exemplar library members belonging to the four numerically largest clusters are shown in Figure 1 (numeric cluster sizes range from 1 to 26 and were labeled sequentially by cluster size, see Table 1 ). For instance, the $\mathrm{R}^{2}$ bridging moiety of cluster-1 may be one or two atoms in length, and the observation of both a thiazole and pyrazole ring within the $\mathrm{R}^{1}$ moiety suggests potential toleration of other fivemembered heterocycles. In the case of cluster 2 , a 1,3,8triazaspiro[4.5]decanone core is acylated with numerous benzofused heterocycles, particularly those with a 5- or 6substituted carboxamide.

Pool 1 (containing libraries 1-10) was screened in parallel against DDR1 and DDR2, and at multiple concentrations of target protein $(3,1$, and $0.1 \mu \mathrm{M})$, leading to the discovery of clusters 2, 3, and 7-9 (Table 1). Clusters that enriched against both DDR1 and DDR2 were hypothesized to be nonselective. Partly to test this hypothesis, exemplars from clusters 8 and 9 were synthesized and, as confirmed by analysis of the screening data, found to be nonselective. Alternatively, clusters 2, 3, and 7 enriched only against DDR1, and all exemplars synthesized from these clusters show at least 10 -fold selectivity over DDR2, and compounds $\mathbf{2 a}$ and $\mathbf{2 b}$ possess greater than 100 -fold selectivity over DDR2.

Exemplars from clusters 2, 3, and 7 were chosen based upon a combination of enrichment magnitude (Table S3), availability of precursors for synthesis, and physicochemical properties. Our laboratory commonly estimates the potency of library members via analysis of enrichment levels while screening at decreasing protein concentrations. ${ }^{28}$ For all interesting clusters derived from libraries $1-10$, lowering the protein concentration (during the incubation step and prior to capture on resin) from 3 to 1 $\mu \mathrm{M}$ led to a complete loss of enrichment. Thus, we predicted that all library members in these clusters would possess at most micromolar equilibrium dissociation constants; indeed, with the exception of $\mathbf{2 b}$, all compounds derived from libraries 1-10 demonstrated low micromolar activities in a binding competition assay (Tables 1 and S1).

Pool 2 was screened against only DDR1 at a single protein concentration $(2 \mu \mathrm{M})$; focusing on libraries $11-16$, we attempted to discover DDR1 selective molecules without the benefit of a parallel DDR2 screen. Libraries 11-16 provided clusters 1, 4-6, 10, and 11 (Tables 1 and S1). Some compounds derived from these clusters show $\sim 10$-fold selectivity over DDR2 (compounds 1a, 5a, 6a, 6b, 10a, and 11a); however, later optimization across all series was unsuccessful in improving and/or maintaining selectivity (data not shown).

Structure-Guided Optimization of DEL-Derived Hits Results in Lead Compound 2.45, a Bioavailable DDR1 Inhibitor. Medicinal chemistry hit expansion included all the clusters listed in Table 1; however, structure-activity relationship (SAR) efforts progressed only for cluster-2. Particularly, we were unable to improve the potency of compounds derived from clusters $6-10$, or the selectivity of compounds derived from clusters 4, 5, and 11. In addition, compounds derived from cluster-1 generally suffered from high lipophilicity (determined by AlogP values employing Pipeline Pilot 9.2) compared to molecules derived from cluster-2. Cluster- 2 was prioritized due to its selectivity over DDR2 and rapid increase in potency upon conducting structure based optimization (discussed below). The spirocyclic core of cluster-2 also attracted our attention since this motif provides distinct space-filling properties due to its high level of three-dimensionality; note that high threedimensionality is reported to positively impact drug-like physical properties. $^{29}$ To the best of our knowledge, the 1,3,8triazaspiro[4.5]decanone template of cluster- 2 has not been described as a central scaffold in the field of receptor tyrosine kinase inhibitors.

The cocrystal structure of the kinase domain of human DDR1 in complex with compound $\mathbf{2 a}$ was determined (Figure 2) as a

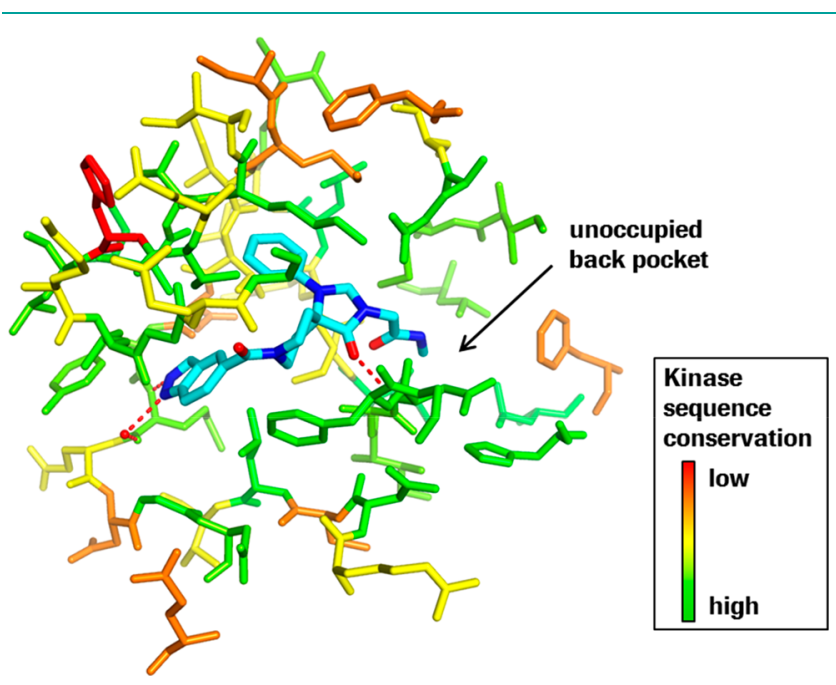

Figure 2. Cocrystal structure of human DDR1 with ligand 2a (PDB code: $6 \mathrm{FEW}$, resolution $1.44 \AA$ ) revealing a type II binding mode and an unoccupied hydrophobic pocket near the terminal amide group. Protein-ligand hydrogen bonds (direct and water-mediated) are highlighted as red, dashed lines. Protein residues are colored by the degree of sequence conservation with respect to the full kinome (for a description of the kinase sequence variability scores that are mapped onto the binding site, see the Methods section). For clarity of view, water molecules are removed except for the one mediating the ligandhinge interaction.

pivotal step for initiating work on this compound series, particularly for rationalizing the original steep SAR of analogues 2a, 2.11, and 2.12 (Table S8), and enabling detailed structureguided compound optimization. As observed for other DDR1 inhibitor series, ${ }^{20,30-33}$ the binding mode is type II with the AspPhe-Gly (DFG) motif in a DFG-out conformation. ${ }^{34}$ This kinase conformation is catalytically inactive because the phenylalanine residue is in a position that blocks binding of ATP. The indazole headgroup is engaged in two hydrogen bonds with Met 704 from the hinge region which links the Nand C-terminal kinase domains. In particular, the indazole nitrogen lone pair makes a direct contact with the backbone amide $\mathrm{NH}$, while the indazole $\mathrm{NH}$ donor contact to the carbonyl oxygen is mediated through a water molecule. Another hydrogen bond is formed between the carbonyl of the spiro scaffold with the $\mathrm{NH}$ backbone of Asp 784, which is part of the DFG motif. The phenyl substituent at the imidazolidinone ring sits in a pocket on top of the gatekeeper residue $\mathrm{Thr} 701$ and is in a protein region with reduced kinome sequence conservation. Most importantly, an unoccupied hydrophobic pocket near the terminal amide of compound $2 \mathbf{a}$ became apparent offering the 
From DELT screen

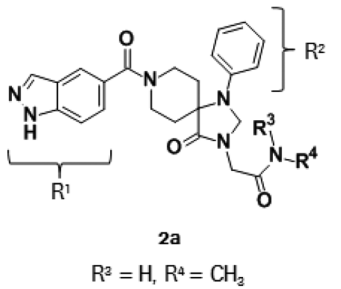

DDR1 IC $\mathrm{IC}_{50}=1.4 \mu \mathrm{M}$

DDR2 IC $_{50}=>167 \mu \mathrm{M}$

$\mathrm{LE}=0.24$

$\log \mathrm{D}=1.70$

LYSA $=13 \mu \mathrm{g} / \mathrm{mL}$

Human $\mathrm{Cl}_{\text {Mic }}=13 \mu \mathrm{L} / \mathrm{min} / \mathrm{mg}$

Mouse $\mathrm{Cl}_{\text {Mic }}=114 \mu \mathrm{L} / \mathrm{min} / \mathrm{mg}$

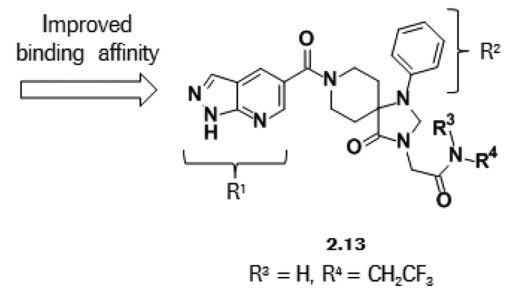

DDR1 IC I0 $_{50}=0.016 \mu \mathrm{M}$

DDR2 $I_{50}=6.3 \mu \mathrm{M}$

$\mathrm{LE}=0.29$

$\log \mathrm{D}=1.92$

LYSA $=1.1 \mu \mathrm{g} / \mathrm{mL}$

Human $\mathrm{Cl}_{\text {mic }} 32 \mu \mathrm{L} / \mathrm{min} / \mathrm{mg}$

Mouse $\mathrm{Cl}_{\text {mic }} 97 \mu \mathrm{L} / \mathrm{min} / \mathrm{mg}$

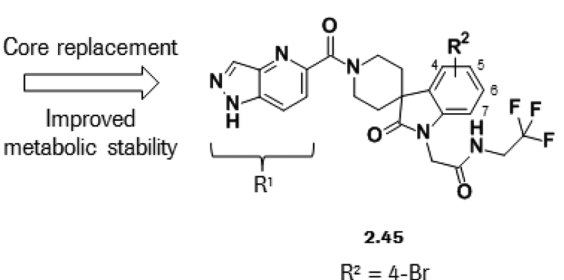

DDR1 IC ${ }_{50}=0.029 \mu \mathrm{M}$

DDR2 IC $_{50}=1.9 \mu \mathrm{M}$

$\mathrm{LE}=0.29$

$\log \mathrm{D}=2.72$

LYSA $=103 \mu \mathrm{g} / \mathrm{mL}$

Human $\mathrm{Cl}_{\text {mic }}=10 \mu \mathrm{L} / \mathrm{min} / \mathrm{mg}$

Mouse $\mathrm{Cl}_{\text {mic }}=10 \mu \mathrm{L} / \mathrm{min} / \mathrm{mg}$

$\mathrm{F}$ (mouse) $=23 \%(\mathrm{PO}), 78 \%(\mathrm{IP})$

Figure 3. Modifications around DELT starting point 2a leading to the discovery of lead DDR1 inhibitor 2.45. Structure and profile of DELT starting point $2 \mathrm{a}$ (left), optimized in vitro compound $\mathbf{2 . 1 3}$ (middle), and proof-of-concept compound lead DDR1 inhibitor 2.45 (right). Note that the stated $\mathrm{IC}_{50}$ values are derived from a binding competition assay employing purified recombinant truncated DDR1 as described in the Methods section.

potential for further activity increase. We used the terminal acetamide of $\mathbf{2 a}$ (see $\mathrm{R}^{3}$ and $\mathrm{R}^{4}$ in Figure 3 ) as the key exit vector to extend toward this pocket; for example, replacing the methyl group of 2a by a slightly larger trifluoromethyl group (2.1) resulted in a $\sim 100$-fold potency gain (Table S8). Gratifyingly, such analogues generally maintain kinase selectivity. Tertiary amides like in $2.7\left(\mathrm{IC}_{50} 0.019 \mathrm{uM}\right)$ do not lead to a further increase in activity but allow the introduction of polar sidechains that help improve the moderate aqueous solubility of 2 a (13 ug/mL vs $177 \mathrm{ug} / \mathrm{mL}$ for 2.10).

The essential role of the kinase hinge binding interaction of the nitrogen lone pair of the indazole (see $\mathrm{R}^{1}$ in Figure 3 ) is corroborated by a significant loss of activity if the indazole is replaced by a pyrrolo-pyridine headgroup as in compound $\mathbf{2 . 1 2}$ $\left(\mathrm{IC}_{50}>167 \mu \mathrm{M}\right.$, Table S8). Moving the nitrogen from position 7 to position $6(\mathbf{2 . 1 5})$ or $4(\mathbf{2 . 1 6})$ in the $1 H$-pyrazolo[3,4b]pyridine headgroup has a strong positive impact on solubility (Table S9). The trifluoromethylacetamide substituent in combination with the pyrrolo-pyridine hinge binding group gave the best overall profile in terms of potency and selectivity over DDR2 (2.13). Further optimization of the phenyl ring (see $\mathrm{R}^{2}$ in Figure 3) was also undertaken; however, the phenyl ring turned out to be very sensitive toward structural modifications as illustrated by a fluoro scan (2.19-2.21).

The metabolic instability of 2.13 , primarily caused by dearylation at N1, precludes its use in in vivo studies (Table S9); thus, employing rational design, we replaced the central core of $\mathbf{2 . 1 3}$ with spiro[indoline-3,4'-piperidine]-2-one (see compound 2.45 in Figure 3). This scaffold modification turned out to be the breakthrough in the lead optimization process since it circumvents the $\mathrm{N}$-dearylation issue while maintaining key binding interactions. As hypothesized, low clearance values in microsomal preparations are observed for this modified series (Table S11), and binding affinity and selectivity is maintained (Table S10) through conservation of the key interactions to the protein and maintaining comparable space-filling properties similar to 2a (Figure 4). A fluoro scan on 2.26 (binding competition $\mathrm{IC}_{50} 0.394 \mu \mathrm{M}$; Table S10) indicated that substitution at position 4 improved potency (2.32 binding competition $\left.\mathrm{IC}_{50} 0.150 \mu \mathrm{M}\right)$, resulting in a potent $4-\mathrm{Br}$ substituent $\left(2.37\right.$ binding competition $\left.\mathrm{IC}_{50} 0.032 \mu \mathrm{M}\right)$ with

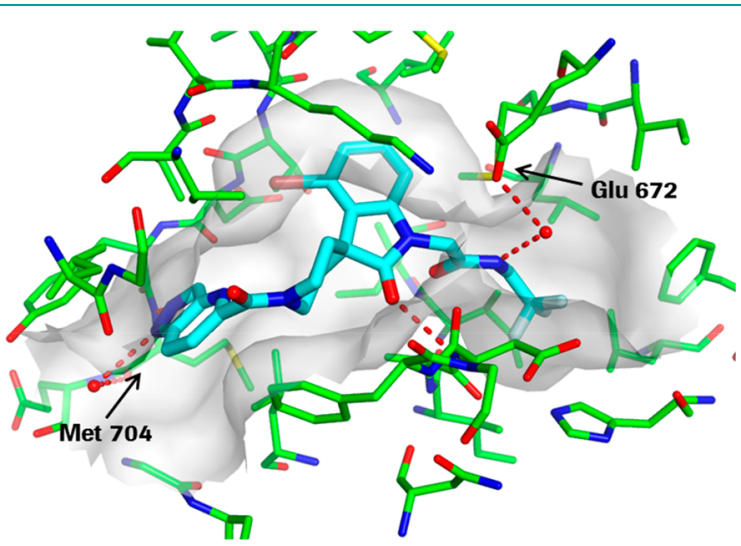

Figure 4. Cocrystal structure of human DDR1 with ligand 2.45 (PDB code: 6FEX, resolution $1.29 \AA$ A). Protein-ligand hydrogen bonds (direct and water-mediated) are highlighted as red, dashed lines. For clarity of view, water molecules are removed except for the two mediating the ligand interaction with the hinge backbone of Met 704 and the side chain of Glu 672 .

acceptable lipophilicity $(\log D 2.72$; Table S11). Further efforts culminated in $\mathbf{2 . 4 5}$ (Figure 3 and Supplemental Figure 3), our lead DDR1 inhibitor, which was chosen for in vivo proof-ofconcept (PoC) studies.

Lead Compound 2.45 Exhibits Remarkable Selectivity, Inhibits DDR1 Phosphorylation and Recruitment of SHC1 in Vitro, and Modulates Phenotype of Collagen Stimulated Renal Epithelial Cells. Compound $\mathbf{2 . 4 5}$ possesses excellent kinome selectivity (Figure 5A) when profiled in an active site-directed competitive binding assay against a kinase panel of 468 kinases at a concentration of $10 \mu \mathrm{M}$ (a concentration 5000 -fold above its $K_{\mathrm{d}}$ of $2 \mathrm{nM}$ for DDR1). For kinase targets that were inhibited greater than $50 \%$ (Table S4), binding constants $\left(K_{\mathrm{d}}\right)$ were determined. Compound $\mathbf{2 . 4 5}$ is 14fold selective over DDR2 and has a selectivity of at least 1400fold over the other profiled kinase targets, demonstrating the outstanding selectivity of the compound. Furthermore, 2.45 displays favorable pharmacokinetic properties (Supplemental Figure 4), favorable physicochemical properties (Table S11), and a clean in vitro safety profile (Supplemental Figure 3 ). We then proceeded to assess if $\mathbf{2 . 4 5}$ compound binding would 


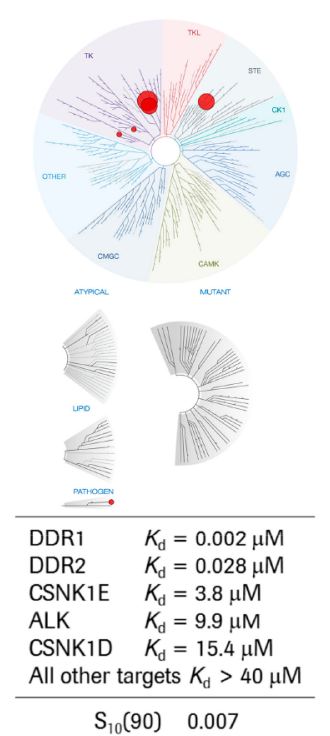

0.007
B

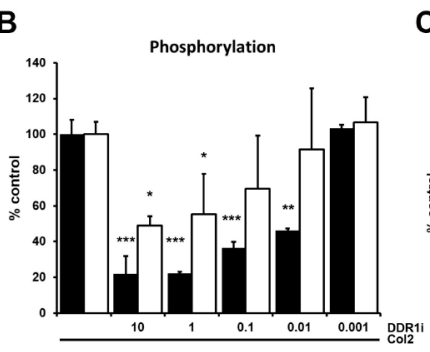

E

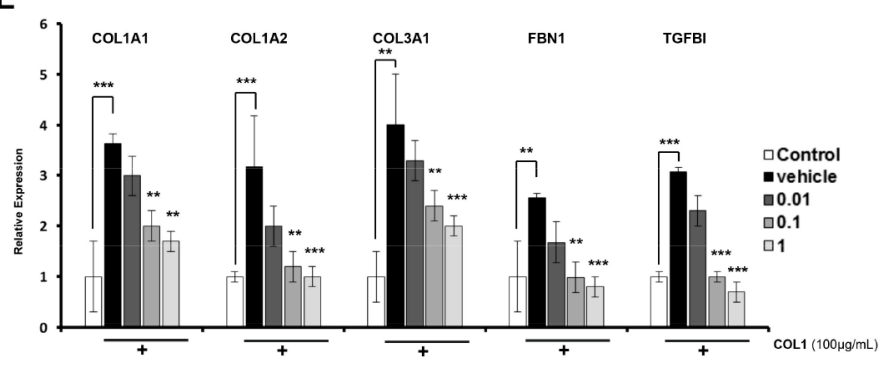

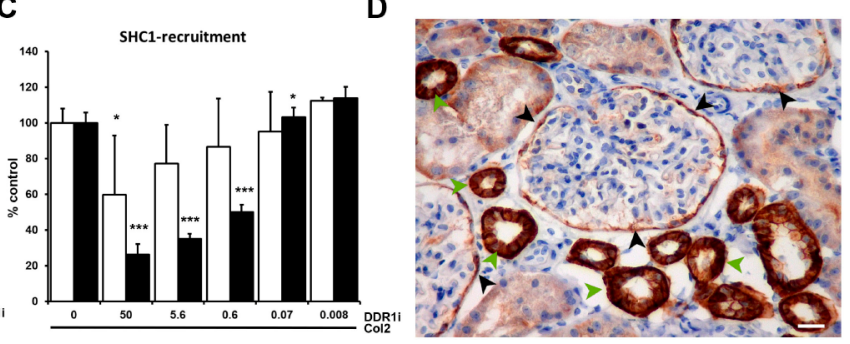

.

Figure 5. Lead compound 2.45 is a selective DDR1 inhibitor and inhibits DDR1 phosphorylation and recruitment of SHC1 in vitro and modulates phenotype of collagen stimulated renal epithelial cells. (A) Graphical representation ("TREEspot Interaction Maps") of selectivity profile of $\mathbf{2 . 4 5}$ tested on 468 kinase targets. Test concentration $10 \mu \mathrm{M}$. Kinases that bind are marked with red circles, where larger circles indicate stronger binding; $K_{\mathrm{d}}$ constants for kinases inhibited with $>50 \%$ at $10 \mu \mathrm{M}$ test concentration; selectivity score $S(90)$ at the test concentration of $10 \mu \mathrm{M}$. (B) Phosphorylation in HT1080 overexpressing DDR1 or DDR2 and (C) SH2 domain complementation assay in cells overexpressing DDR1 or DDR2 treated with collagen type 2. (D) DDR1 expression in a Alport patient using an in-house raised anti-human DDR1 selective antibody. Distal tubular epithelial cell DDR1 positivity indicated by green arrowheads and parietal epithelial cell indicated with black arrowheads. (E) Quantitative RT-PCR for COL1A1, COL1A2, COL3A1, FBN1, or TGFB1 in HKC8 cells overexpressing DDR1 upon collagen type 2 stimulation. $* * p<0.05$, $* * * p<0.001, t$ test.

translate into inhibition of DDR1 phosphorylation in a cellular context. Compound $\mathbf{2 . 4 5}$ showed a clear dose-dependent inhibition of DDR1 phosphorylation in HT1080 cells overexpressing DDR1, with greater than $70 \%$ inhibition of phosphorylation at a concentration of $1 \mu \mathrm{M}$, and retaining selectivity over inhibition of DDR2 (Figure 5B). Compound $\mathbf{2 . 4 5}$ was further characterized in a $\mathrm{SH} 2$ domain complementation assay where it displayed reasonable selectivity over DDR2; this assay is a robust, highly sensitive and easy-to-use, cell-based functional assay for monitoring DDR1 and DDR2 activation states (Figure 5C).

The impact of DDR1 inhibition on cellular signaling was assessed using a DDR1 inducible construct transfected in a human renal epithelial cell line HKC8. ${ }^{30}$ The HKC8 cell line chosen as the expression profile of DDR1 in human Alport syndrome renal tissue is largely limited to parietal epithelial cells (PEC, black arrowheads) and distal tubular cells (DTC, green arrowheads) as assessed by immunohistochemistry (IHC) using a specific rabbit monoclonal anti-human DDR1 antibody raised in-house $^{31}$ (see Figure 5D). Collagen type I was selected to stimulate HKC8 cells based on previous super-resolution microscopy suggesting that PECs (proximal tubule cells) and DTCs (distal tubule cells) are exposed to collagen in Alport syndrome COL $4 \mathrm{a}^{-/-}$mice but not in normal WT mice. ${ }^{32}$ (note that collagen types II and IV have similar effects as collagen type I, and collagen I was retained for the figure due to a superior assay window; for comparison between the different collagen types, please see Supplemental Figure 7).

Stimulation with collagen type I alone induced a significant increase of COL1A1, COL1A2, COL3A1, FBN1, and TGBFI gene expression. Pretreatment of the cells with compound $\mathbf{2 . 4 5}$ caused a dose-dependent inhibition of expression of those genes (Figure 5E).
Lead Compound 2.45 Modulates the Degree of Fibrosis in Col4a3 ${ }^{-1-}$ Mice in a Therapeutic Regime. We assessed the ability of compound $\mathbf{2 . 4 5}$ to reduce kidney cortex phosphorylation of DDR1 and to rescue mice with Alport syndrome from renal failure and kidney fibrosis. The expression of total and phosphorylated DDR1 is increased in the kidney cortex of COL4a3 $3^{-/-}$when compared to Col4a ${ }^{+/+}$(WT). Treatment with 2.45 (90 $\mathrm{mg} / \mathrm{kg}$ ) reduces DDR1 phosphorylation, but not total DDR1 expression in COL4a $3^{-/-}$mice (Figure 6). The reduction in phosphorylated DDR1 is associated with a significant reduction in albumin/creatinine ratio and blood urea nitrogen (BUN, Figures $7 \mathrm{~A}$ and $7 \mathrm{C}$ ), while only a nonsignificant trend in reduction of serum creatinine was observed (Figure 7B). Treatment of Col4A3 $3^{-/-}$mice with $\mathbf{2 . 4 5}$ resulted in a significant reduction of fibrosis evaluated by Picro Sirius Red (Figure 7D), smooth muscle actin staining (Figure $7 \mathrm{E}$ ), and collagen I accumulation (Figure $7 \mathrm{~F}$ ).

Conclusion. In the present work we show, for the first time, that DDR1 inhibition, achieved with a DEL-derived small molecule, translates into (A) prevention of phenotypical modulation of collagen-stimulated renal tubular epithelial cells and, more importantly, (B) reduced renal fibrosis and renal function preservation in Col4A3 $3^{-/-}$mice, the mouse model of Alport syndrome when applied in a therapeutic regime.

Our results translate into a treatment paradigm that previously had been investigated only using a gene deletion or silencing approach. ${ }^{14-18,25,26}$ Although DDR1 is a biologically appealing target, it has proven challenging and has resulted in only three publications to date. Most pertinent to our work, small molecule DDR1 inhibitors have been reported, ${ }^{19,33}$ but lack selectivity across the kinome. Indeed, the most advanced reported DDR1 inhibitors [structures 21 and 22 in Supplemental Figure $5^{19,34}$ ] were modeled on nonselective tyrosine kinase inhibitors including imatinib, nilotinib, and dasatinib 
A
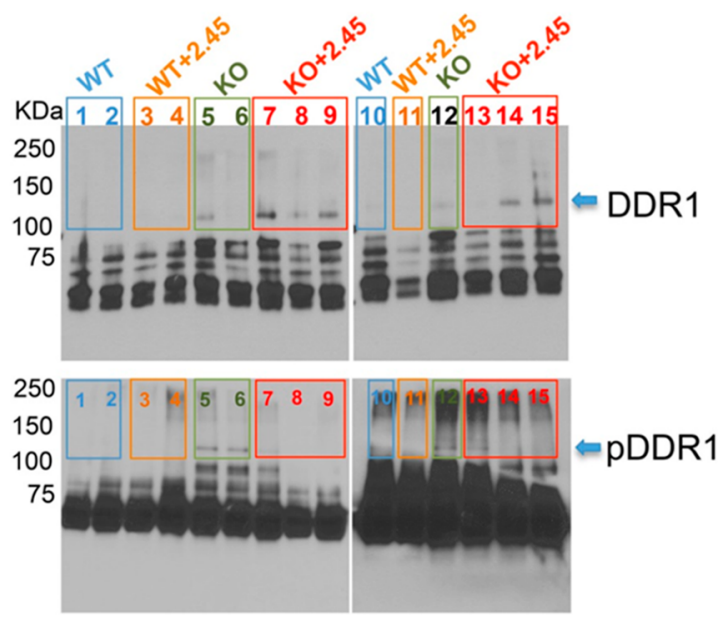

B
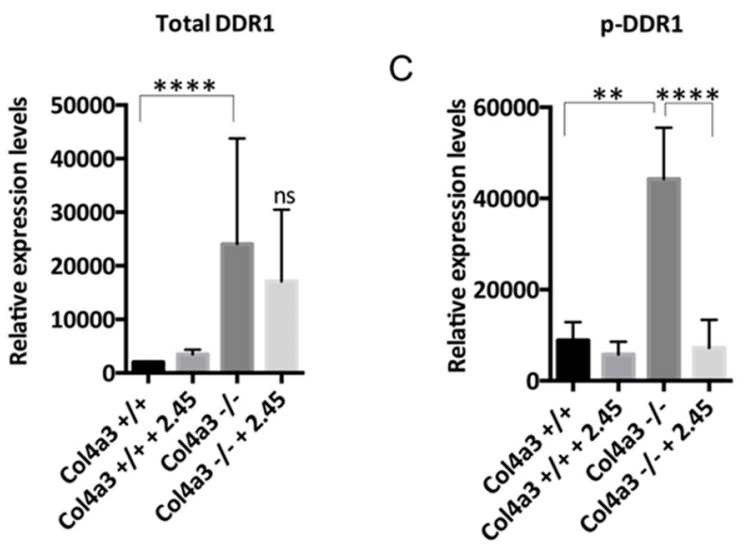

Figure 6. Compound 2.45 reduces phosphorylated DDR1 in whole kidney lysates. Col4a3 knockout mice $\left(\mathrm{Col}_{4} \mathrm{a}^{-/-}\right)$and wild type littermates $\left(\mathrm{Col}_{4} 3^{+/+}\right)$were injected intraperitoneally with 2.45 (90 $\mathrm{mg} / \mathrm{kg}$ ) or vehicle on a daily basis. Four groups of mice were analyzed: $\mathrm{Col}_{43} 3^{+/+}(n=8), \mathrm{Col}_{4} \mathrm{a}^{+/+} 2.45(n=8), \mathrm{Col}_{4} \mathrm{a}^{-/-}(n=6)$, and $\mathrm{Col}_{4 \mathrm{a} 3^{-/-}} 2.45(n=10)$. (A) Two representative Western Blots on eluates from whole kidney lysates after immunoprecipitation ot total DDR1 are shown. Numbers 1-15 indicate individual animals. (B) Bar graph analysis showing that expression of total DDR1 increased in Col4a3 knockout mice compared to wild type mice but is not affected by $\mathbf{2 . 4 5}$ treatment, $* * * * p<0.0001, t$ test. (C) Treatment with $\mathbf{2 . 4 5}$ significantly reduces the levels of pDDR1 in Col4a3 knockout mice compared to controls, $* * p<0.01, * * * * p<0.0001, t$ test.

[structures $18-20^{35}$ in Supplemental Figure 5]. Screening of a focused library of approximately 2000 compounds originally designed as Bcr-Abl inhibitors followed by structural optimization led to the identification of a new class of DDR1 inhibitors (23). ${ }^{19}$ Fragment-based screening of a library of 1500 compounds in combination with structural biology and computational modeling allowed identification of another class of DDR1/2 ligands [structure 24 in Supplemental Figure $5^{20}$ ]. Lastly, virtual screening of a commercially available library of approximately 230000 compounds was used to identify new DDR1 inhibitors [see Supplemental Figure 5 for structures 18$\left.25^{21}\right]$.

The challenge in discovering a DDR1 inhibitor selective against the entire kinome resides in the limited chemical diversity used to derive new molecules; new chemical starting matter is generally recycled from previous ATP binding pocket optimization efforts, and ATP binding pocket homology is highly conserved across all RTKs. ${ }^{22}$ In contrast to previous attempts, we decided to explore the chemical space offered by DNA encoded libraries (DELs), a technology increasingly used in drug discovery for hit generation. ${ }^{36,37}$ Due to the high rate of false-negatives inherent in DEL screening, the effective numerical size our combinatorically generated encoded compound collection is likely less than the calculated theoretical value of $\sim 10^{10} .{ }^{38}$ Still, the effective numerical size of our encoded compound collection is likely larger than that of traditional pharmaceutical industry collections of $\sim 10^{6}$ compounds. ${ }^{39}$ Additionally, the chemical space contained within our DEL pool is significantly different from published chemical space and the Roche proprietary compound collection. ${ }^{27}$

DEL screens have been previously described against kinases, including Bruton's tyrosine kinase; ${ }^{40}$ however, the use of parallel screening to discover a selective kinase inhibitor has never been reported. The only reported parallel DEL screens are a proof of concept experiment employing serum albumin from different species. ${ }^{41}$ Our data, for the first time, indicates that parallel DEL screening may be used to predict compound specificity and streamline the process of discovering selective molecules, resulting in an in vitro selective DDR1 inhibitor.

Starting from the moderately potent hit molecule $2 \mathrm{a}$, and guided by biostructural design to optimize DDR1-ligand interactions and molecular properties, we developed the potent and highly selective DDR1 inhibitor 2.13. Superposition of the DDR1 cocrystal structure of 2a with those of other DDR1 inhibitors (Supplemental Figure 6) reveals three key aspects that might contribute to the kinase selectivity of the series discussed in this paper. Compound 2a (a) protrudes deeper into the back pocket, where there is less conservation of amino acids (highlighted in Figure 2), (b) has greater three-dimensional character around the spiro core, and (c) interacts differently with the backbone NH donor of Asp784 (part of the DFG motif) (Figure S6). Though potent, 2.13 suffers from high clearance in microsomal preparations leading to poor metabolic stability that was ultimately fixed by changing the core structure as part of the medicinal chemistry strategy, resulting in the generation of lead DDR1 inhibitor 2.45. The binding selectivity of $\mathbf{2 . 4 5}$ for DDR1 over its close analogue DDR2 is 65- and 14-fold as measured in competition (Table S10) and direct binding assays, respectively (employing truncated recombinant protein). Importantly, the binding affinity of $\mathbf{2 . 4 5}$ for DDR1 translates into significant submicromolar DDR1 autophosphorylation inhibition in a cellular assay, while inhibition of DDR2 appears insignificant (Figure 5B). Additionally, $\mathbf{2 . 4 5}$ halts collagen-induced phenotypical modulation of renal epithelium as demonstrated by a dose response titration of activation markers COL1A1, COL1A2, COL3A1, FBN1, or TGBFI (Figure 5E); these results are highly relevant and suggest the potential of in vivo fibrotic modulation.

The above results prompted us to test 2.45 in $\mathrm{Col}_{4 a 3^{-/-}}$mice in a therapeutic regime. Compound 2.45 reduces DDR1 phosphorylation in $\mathrm{Col}_{4} \mathrm{a}^{-/-}$mice (Figure 6), and significantly improves renal glomerular function as measured by albumin/ creatinine ratio and BUN (Figure 7A-C). Renal function improvement is accompanied by reduced renal parenchymal fibrosis (Figure 7D-I). These observations are consistent with previous preclinical studies using double $\mathrm{KO}$ mice for $\mathrm{Col}_{4} \mathrm{a3}^{-/-}$ and $D d r^{-/-}$, which reported reduced inflammation, fibrosis, improved kidney function and increased lifespan compared to $\mathrm{Col}_{4 a 3^{-/-25,26}}$

Though our experiments were not aimed at addressing the mechanisms whereby inhibition of DDR1 phosphorylation/ 


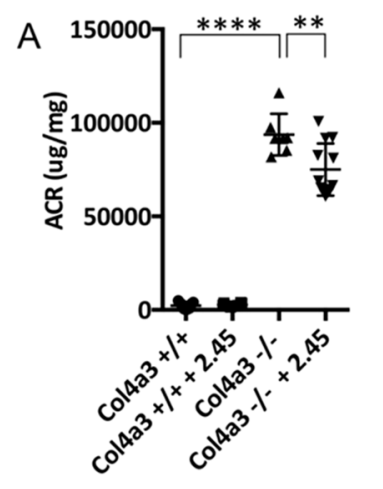

D

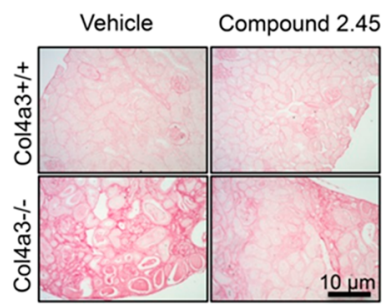

G

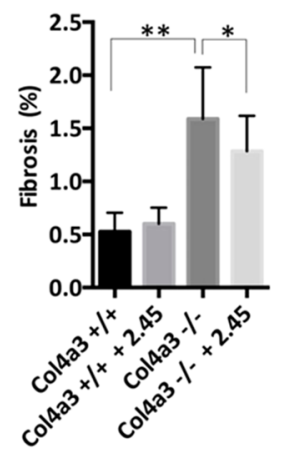

B

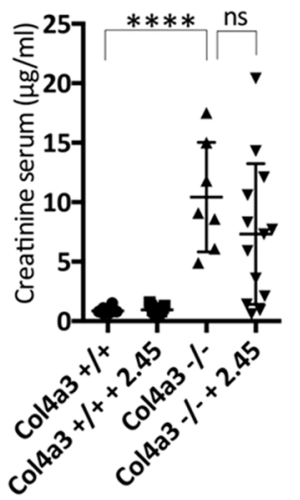

E

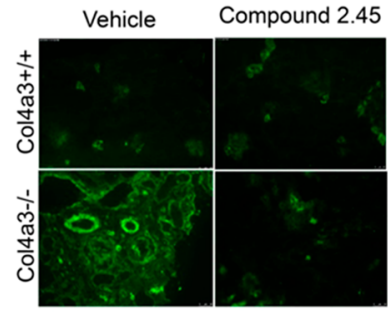

$\mathrm{H}$

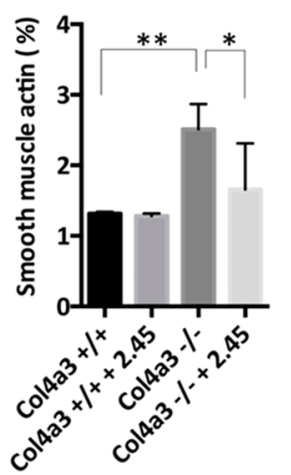

C

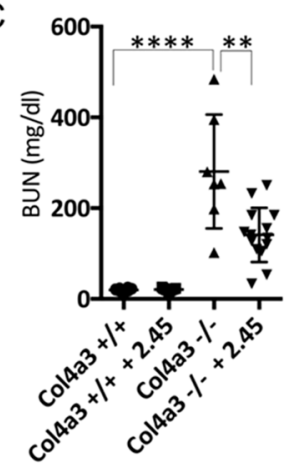

$\mathrm{F}$

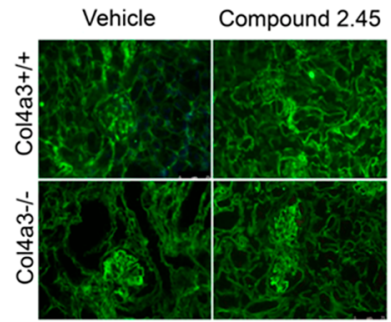

I

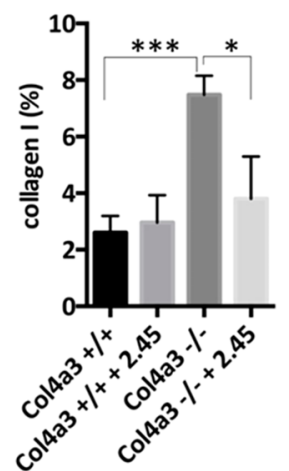

Figure 7. DDR1 inhibition with $\mathbf{2 . 4 5}$ preserves renal function and reduces renal fibrosis in Col4a3 deficient mice. Four groups of mice were analyzed: $\mathrm{Col}_{4} \mathrm{a}^{+/+}(n=10), \mathrm{Col}_{4} \mathrm{a3}^{+/+} 2.45(n=11), \mathrm{Col}_{4} \mathrm{a}^{-/-}(n=11)$, and $\mathrm{Col}_{4} \mathrm{a}^{-/-} 2.45(n=14)$. (A) 2.45 treatment of Col4a3 knockout mice results in a reduction in the albumin/creatinine ratio compared to control. $* * p<0.023$, ****p $<0.0014$. (B) Serum creatinine levels are increased in Col4a3 knockout mice compared to controls but were not affected by treatment with $\mathbf{2 . 4 5}$, **** $p<0.0001, t$ test. (C) Graph analysis showing that serum BUN levels are significantly increased in Col4a3 knockout mice compared to wild type, whereas treatment with 2.45 prevents increases in serum BUN levels in Col4a3 knockout mice. ${ }^{* *} p<0.005$, ${ }^{* * *} p<0.0001, t$ test. (D) Picro Sirius Red staining of kidney sections $(4 \mu \mathrm{m})$ in Col4a 3 knockout mice $(10 \times)$. (E) Bar graph analysis of PSR staining demonstrates increased fibrosis in Col4a3 knockout mice when compared to wild type littermates. Treatment with 2.45 significantly reduces fibrosis in Col4a 3 knockout mice. ${ }^{*} p<0.01, * * p<0.005$, $t$ test. (F) $\alpha$-smooth muscle actin staining of kidney sections $(4$ $\mu \mathrm{m})$ in Col4a3 knockout mice (20×). (G) Bar graph analysis of $\alpha$-smooth muscle actin staining demonstrates high fibrotic lesions in Col4a3 knockout mice when compared to wild type littermates. Treatment with 2.45 significantly reduces fibrosis in Col4a3 knockout mice. $* p<0.004, * * p<0.032, t$ test. (H) Collagen I staining of kidney sections $(4 \mu \mathrm{m})$ in Col4a3 knockout mice (20X). (I) Bar graph analysis of collagen I staining showed elevated expression of fibrosis in Col4a 3 knockout mice when compared to wild type littermates. Treatment with 2.45 significantly reduces fibrosis in Col4a 3 knockout mice. $*_{p}<0.01, * * * p<0.0007, t$ test.

activation leads to a beneficial effect in $\mathrm{Col}_{4 a 3^{-/-}}$mice, it is hypothesized that blocking DDR1 kinase activity in vivo reduces the proinflammatory phenotype and the activation, regeneration and maladaptive repair status ${ }^{42}$ of tubular epithelial cells, and PECs (shown to express DDR1 in Alport syndrome biopsies by IHC). Ultrastructural studies have in fact shown that collagen is localized to the inner layer of the glomerular basement membrane (GBM) in healthy subjects, but less so in Alport

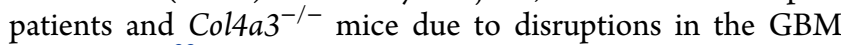
architecture. ${ }^{32}$ This disruption may expose DDR1 to its ligand, triggering the phenotypical modulation of tubular cells and PECs toward a profibrotic status, in agreement with our in vitro experimental results stimulating $\mathrm{HKC} 8$ cells with collagen. Causal association between a profibrotic status of epithelial (in both PECs and tubular cells) and renal function deterioration, paralleled by fibrosis, has been mechanistically documented in genetically engineered mouse models overexpressing TGF- $\beta 1^{43}$ and in models of targeted epithelial cell injury. ${ }^{42}$ In our in vitro experiments, aimed at mimicking exposure of epithelial cells to collagen in vivo, we were able to show that DDR1 inhibition downregulates pro-fibrotic status of $\mathrm{HKC} 8$ cells (with for instance a clear dose dependent reduction of TGF- $\beta 1$ expression in the presence of 2.45), suggesting that this might be the DDR1 mode of action $(\mathrm{MoA})$ in vivo.

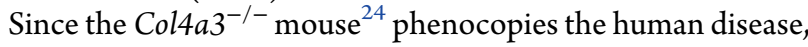
compound 2.45 and close analogues of even higher potency, may be a promising intervention for the treatment of Alport syndrome patients in combination with the current standard of care. Similar results using Col4a3/Ddr1 double knock out mice treated with ACEi Ramipril have been reported ${ }^{44}$ and are 
supportive and suggestive that DDR1 MoA might be combinable and synergistic with current patient treatment paradigm aiming to reduce proteinuria and intraglomerular pressure via interference with the renin-angiotensin-aldosterone system (RAAS). ${ }^{45}$ The synergistic aspect is of particular value in regard to the current treatment paradigm for Alport pediatric patients ideally enabling clinicians to adopt and add-on medication approach when RAAS targeting medications, whose safety is currently under evaluation in a dedicated study, ${ }^{46}$ could not be dosed higher due to individual patient tolerability levels.

More generally, we do believe that our results, obtained in $\mathrm{Col}_{4 \mathrm{a}} 3^{-1-}$ mouse, a recognized mouse model for $\mathrm{CKD},{ }^{47} \mathrm{might}$ have a wider significance for the broader community of CKD patients. Alport syndrome shares in fact multiple pathophysiological facets of CKD. The similarity goes as far as sharing the same treatment paradigm (i.e., interference with the reninangiotensin-aldosterone system). Thus, we speculate that selective pharmacological inhibition of DDR1 might be an interventional strategy also in the context of an established renal lesion and impaired renal function in CKD, a disease affecting $10 \%$ of the global population ${ }^{48}$ consuming in just the United States $6.7 \%$ of the total Medicare budget to care for less than $1 \%$ of the covered population.

\section{METHODS}

CEREP Receptor Panel. Compound binding was calculated as percent inhibition of the binding of a radioactively labeled ligand specific for each target. Compound enzyme inhibition effect was calculated as percent inhibition of control enzyme activity.

Kinase Assays: DDR1 and DDR2 Binding Competition Assay. This assay is based on the intracellular domain of the DDR1 and DDR2 protein, respectively which contains the kinase active site. The recombinant protein additionally carries a GST-tag that can be recognized by an Eu-labeled anti-GST antibody. A tracer compound binding to the active site is labeled with a dye so that a FRET donoracceptor pair can be formed. Excitation energy absorbed by the Europium complex ( $350 \mathrm{~nm}$ flash light or pulsed laser) is transferred to a suitable fluorescent dye, if it is in close proximity. Compounds binding competitively with the tracer molecule will displace the bound tracer molecules and reduce the FRET signal in a dose dependent manner. Due to the long lifetime of the $\mathrm{Eu}^{3+}$ excited state, the emission of the donor and the acceptor can be measured in time-gated mode such that most of the intrinsic fluorescence contributions have already decayed. This results in high sensitivity, excellent reproducibility and high data quality. This sensitive detection method enables protein concentrations below $20 \mathrm{nM}$.

Protein (Carna Biosciences, Inc., Kobe, Japan), tracer, and labeled antibody (Thermo Fischer Scientific, Waltham, MA) were obtained from commercial sources. The assay was performed in 384 low volume microtiter plates with a final volume of $15 \mu \mathrm{L}$. Dose-response curves were generated from 16 compound dilutions in DMSO as solvent compound dilutions, a solution containing protein and labeled antibody, and a solution containing the tracer which is added in the last step. The fluorescence of donor and acceptor were then measured after $1 \mathrm{~h}$ incubation at RT. Every assay run was quality-controlled with dose-response curves for two reference compounds.

Kinase Assay Panel. The KINOMEscan screening platform (Discoverx Corporation, San Diego, CA, DiscoverX scanMAX Kinase Assay Panel) employing an active site-directed competition binding assay was used to quantitatively measure interactions between the two Roche DDR 1 inhibitors on and 468 kinases and disease relevant mutant variants. In brief, T7 kinase-tagged phage strains were grown in parallel in 24-well blocks or 96-well blocks in an E. coli host derived from the BL21 strain. E. coli were grown to log-phase and infected with T7 phage from a frozen stock (multiplicity of infection $=0.4$ ) and incubated with shaking at $32{ }^{\circ} \mathrm{C}$ until lysis $(90-150 \mathrm{~min})$. The lysates were centrifuged $(6000 \mathrm{~g})$ and filtered $(0.2 \mu \mathrm{m})$ to remove cell debris. The remaining kinases were produced in HEK-293 cells and subsequently tagged with DNA for qPCR detection. Streptavidin-coated magnetic beads were treated with biotinylated small molecule ligands for $30 \mathrm{~min}$ at RT to generate affinity resins for kinase assays. The liganded beads were blocked with excess biotin and washed with blocking buffer (SeaBlock (Pierce), 1\% BSA, $0.05 \%$ Tween 20, $1 \mathrm{mM} \mathrm{DTT)} \mathrm{to} \mathrm{remove} \mathrm{unbound}$ ligand and to reduce nonspecific phage binding. Binding reactions were assembled by combining kinases, liganded affinity beads, and the two test compounds in $1 \times$ binding buffer $(20 \%$ SeaBlock, $0.17 \times$ PBS, $0.05 \%$ Tween 20, $6 \mathrm{mM}$ DTT). Test compounds were prepared as $40 \times$ stocks in $100 \%$ DMSO and directly diluted into the assay. All reactions were performed in polypropylene 384-well plates in a final volume of 0.02 $\mathrm{mL}$. The assay plates were incubated at RT with shaking for $1 \mathrm{~h}$ and the affinity beads were washed with wash buffer $(1 \times$ PBS, $0.05 \%$ Tween $20)$. The beads were then resuspended in elution buffer ( $1 \times$ PBS, $0.05 \%$ Tween $20,0.5 \mu \mathrm{M}$ nonbiotinylated affinity ligand) and incubated at RT with shaking for $30 \mathrm{~min}$. The kinase concentration in the eluates was measured by qPCR. The selectivity score (S-score) was calculated for both compounds. The compounds were screened at the concentrations requested, and results for primary screen binding interactions were reported as percent competition (\% competition).

Selectivity Score (S-Scores). Selectivity score or S-score is a quantitative measure of compound selectivity. It is calculated by dividing the number of kinases that compounds bind to by the total number of distinct kinases tested, excluding mutant variants.

$$
S=\text { no. of hits/no. of assays }
$$

This value can be calculated using \% Ctrl as a potency threshold (below) and provides a quantitative method of describing compound selectivity to facilitate comparison of different compounds.

$$
\begin{aligned}
S(65)= & (\text { no. of nonmutant kinases with \%Comp }>65) \\
& /(\text { no. of nonmutant kinases tested }) \\
S(90)= & (\text { no. of nonmutant kinases with\%Comp }>90) \\
& /(\text { no. of nonmutant kinases tested }) \\
S(99)= & (\text { number of nonmutant kinases with\%Comp }>99) \\
& /(\text { no. of nonmutant kinases tested })
\end{aligned}
$$

Sequence Variability Score. Kinome sequence variability scores $S_{k s v}^{i, j}$ for a given kinase $i$ at residue position $j$ are calculated as

$$
S_{k s v}^{i, j}=1-\frac{\text { no. of matching kinases }}{\text { total no. of kinases }}
$$

where the numerator is the number of kinases that have the same residue at position $j$ than DDR1 and the denominator is the number of kinases included in the analysis, which is 491 in our case. Our analysis is based on an internal global kinase sequence alignment. Scores $S_{\mathrm{ksv}}^{\mathrm{ijj}}$ can range from 0 to 1 and are mapped to the following color-coding scheme, where high kinase sequence conservation (low $S_{\mathrm{ksv}}^{i, j}$ scores) is shown in green and low kinase sequence conservation (high $S_{\mathrm{ksv}}^{i, j}$ scores) is highlighted in red. The kinome sequence analysis visualization is implemented in Proasis (ref: Proasis, version 3; Desert Scientific Software: Sydney, Australia).

$$
\begin{array}{ll}
S_{\mathrm{ksv}}^{i, j} \leq 0.5 & \text { green } \\
0.5<S_{\mathrm{ksv}}^{i, j} \leq 0.75 & \text { chartreuse } \\
0.75<S_{\mathrm{kvv}}^{i, j} \leq 0.85 & \text { yellow } \\
0.85<S_{\mathrm{ksv}}^{\mathrm{i} j} \leq 0.95 & \text { orange } \\
0.95<S_{\mathrm{ksv}}^{i, j} & \text { red }
\end{array}
$$

Pharmacokinetic Studies. The routes of administration and dosing-regimes for the study were based on pharmacokinetic studies. Compound 2.45 was formulated as a microsuspension in a vehicle (1.25\% hydroxypropylmethylcellulose (HPMC) and $0.1 \%$ docusate sodium (DOSS) ) and administered by intraperitoneal application at 9 $\mathrm{mL} / \mathrm{kg}$. 
Pharmacokinetics of $\mathbf{2 . 4 5}$ was investigated in a separate group of male C57/B16 mice (Figure 1). The compound was administered by intraperitoneal application or via oral gavage, at $10 \mathrm{mg} / \mathrm{kg}$. Plasma samples were collected at $0.25,0.5,1,2,4,7$, and $24 \mathrm{~h}$ postdose. Concentrations in mouse plasma samples and dosing solutions were determined using a high performance liquid chromatography-tandem mass spectrometry (HPLC-MS/MS) method.

2.45 Estimated Pharmacodynamics. Estimation of inhibition of DDR1-phosphorylation were calculated from the observed plasma concentrations in relationship to the in vitro $\mathrm{IC}_{50}$ of $0.0256 \pm 0.002 \mu \mathrm{M}$ for $\mathbf{2 . 4 5}$ against human DDR1, accounting for mouse plasma protein binding of $95.3 \%$.

Thus, $>80 \%$ DDR1-phosporylation inhibition in average over $24 \mathrm{~h}$ in vivo was estimated from the observed plasma concentrations of $\mathbf{2 . 4 5}$ on daily treatment of Alport mice with $90 \mathrm{mg} / \mathrm{kg}$ ip.

Generation of HT1080 Double-Stable Tet-Off Cell Line Overexpressing DDR1or DDR2. DDR1 or DDR2 was cloned BamH1/Not1 in modified pTRE-Tight (Clontech) Hygro, containing a modified TRE (TREmod) upstream of an altered minimal CMV promoter $(\operatorname{PminCMV} \Delta)$. On day 1 , cells were seeded $1 \times 10^{6}$ cells of the "best" TetR-expressing clone per $10 \mathrm{~cm}$ plate using a standard growth medium supplemented with certified tetracycline-free serum (Invitrogen; ref 16000-014). On day 2 cells, were transfected with $2 \mu \mathrm{g}$ of pTRE-Tight using Fugene 6 (Promega). On day 3, standard growth medium containing $500 \mu \mathrm{g} / \mathrm{mL}$ Neo and $500 \mu \mathrm{g} / \mathrm{mL}$ Hygro was added. On day 4 , cells were split at $1 / 5,1 / 25,1 / 50$, and $1 / 100$ using $10 \mathrm{~cm}$ plates and standard growth medium containing $500 \mu \mathrm{g} / \mathrm{mL}$ Neo and $500 \mu \mathrm{g} / \mathrm{mL}$ Hygro. Cells were then checked daily change the standard growth medium containing Neomycin and Hygromycin every 3-4 days. After 2 weeks, (Neo/Hygro) double-resistant colonies appeared. Colonies reaching approximately $5 \mathrm{~mm}$ diameter were picked using cloning cylinders. Particular care was taken to isolate at least 24 individual clones expanded subsequently in 24-well tissue culture plate and then further expanded. After 24-96 h of incubation with/or without Doxycycline cells were harvested and tested in order to assess tetracycline-inducible expression.

In Vitro Characterization of Compound 2.45.: DDR1 Phosphorylation. DDR1 phosphorylation was evaluated using an ELISA-type assay. HT1080 overexpressing cells from a frozen aliquot were plated (at $10^{4}$ cells $/ 100 \mu \mathrm{L}$ media) into a 96-well plate and rested overnight. Medium was carefully replaced with $100 \mu \mathrm{L}$ of fresh DMEM media devoid of FCS and doxycyclin and incubated for $24 \mathrm{~h}$ at $37 \mathrm{C}$. On day 3, medium was changed again and cells were kept in $80 \mu \mathrm{L}$ of fresh medium. Serial dilutions of compounds were prepared separately from $10 \mathrm{mM}$ DMSO stocks. A volume of $10 \mu \mathrm{L}$ of diluted compounds was added to the cells at final $0.1 \%$ DMSO in media in duplicates. The concentration range covered values from 10000 to $0.1 \mathrm{nM}$ in nine steps. After a $15 \mathrm{~min}$ incubation, $10 \mu \mathrm{L}$ of collagen II (DiscoverX final concentration $50 \mu \mathrm{g} / \mathrm{mL}$ ) was added to the cells to stimulate the DDR1 receptor. After $18 \mathrm{~h}$ incubation at $37^{\circ} \mathrm{C}$, cells were lysed with $100 \mu \mathrm{L}$ $1 \times$ lysis buffer (prepared fromCell Signaling, \#9803 and $1 \mathrm{mM} \mathrm{PMSF}$, Sigma \#93482-50 mL-F), incubated for $10 \mathrm{~min}$ at $4{ }^{\circ} \mathrm{C}$, and frozen at $-80^{\circ} \mathrm{C}$. The amount of phosphorylated DDR1 was detected using the PathScan PhosphoDDR1 sandwich ELISA kit (Cell Signaling, ref 7863) following the product protocol from the thawed lysate. Normalized percent inhibition values of phosphorylated DDR1 were calculated from measuring absorbance at $450 \mathrm{~nm}$ and relating these values to $0 \%$ and $100 \%$ inhibition determined on the same assay plate by either adding collagen and DMSO or just DMSO to the cells.

In Vitro Characterization of Compound 2.45: Second Messenger Recruitment. Recruitment of second messenger was evaluated using U2OS PathHunter DDR1 (DiscoverX \#93-0894U3) functional cell lines. The cells are engineered to coexpress a ProLink (PK) tagged DDR1, an enzyme acceptor (EA) tagged SH2 or SH1 domain. DDR1 cells, after thawing from a banked vial, were cultured for 1 day in FCS containing antibiotic-free media and then for 3 days in standard culture media (DiscoverX medium K \#10-241 with serum \#10-032 and antibiotics \#30-481). Using detachment reagent (DiscoverX \#92-009) and plating medium (DiscoverX \#93-0563), cells were distributed into 384-well assay plates (Corning \#3707) at
5000 cells/well in $20 \mu \mathrm{L}$ of media (DiscoverX \#92-0018). After $60 \mathrm{~min}$ incubation at $37^{\circ} \mathrm{C}$, prediluted compounds were added. Final DMSO concentration was $0.5 \%$, and compounds covered a range of $50 \mu \mathrm{M}$ to $0.03 \mathrm{nM}$ (14 steps). Following another incubation step at $37^{\circ} \mathrm{C}$ for $1 \mathrm{~h}$, cells were stimulated by addition of $5 \mu \mathrm{L}$ of a solution of collagen II (DiscoverX \#92-1090) in PBS containing 0.1\% BSA. After mixing for 2 min at $700 \mathrm{rpm}$, cells were incubated $24 \mathrm{~h}$ at $37^{\circ} \mathrm{C}$. Detection of the phosphorylation was done by adding $15 \mu \mathrm{L}$ of detection reagents from DiscoverX (\#93-0001, \#30-404, \#10-068, and \#10-069) and reading the luminescence generated from by the converted galactosidase substrate with an Envision (PerkinElmer) reader. Normalization again was done by referencing to collagen and DMSO and DMSO only control wells.

In Vitro Characterization of Compound 2.45: Phenotypical Modulation in HKC8 Cells. Assessment of DDR1-induced phenotypical modulation in HKC8 cells was performed using HKC8DDR1 tg cells. Cells were plated and rested overnight. Cells were incubated in RPMI-1640 containing 1\% serum and supplemented with different concentrations of DDR1 inhibitor for $1 \mathrm{~h}$ followed by additional treatment with type I collagen $100 \mu \mathrm{g} / \mathrm{mL}$ (Nitta Gelatin, Japan). Total RNA was isolated and amplified using an RNeasy Mini kit (Qiagen) and Transcriptor Universal cDNA Master (Roche) according to manufacturer's instructions. Quantitative RT-PCR was performed on a LightCycler LC480 (Roche) for COL1A1, COL1A2, COL3A1, FBN1 or TGFB1. Relative gene expression was calculated with the $2^{-\Delta \mathrm{Ct}}$ method using GAPDH as an endogenous control.

Anti-DDR1 Antibody Specificity Testing Using DDR1 or DDR2 Expressing Cancer Cell Lines. Human pancreatic cancer CFPAC-1 and PANC-1 cells were a gift from Dr. Howard Crawford, University of Michigan. CFPAC-1 cells were maintained in IMDM supplemented with $10 \%$ fetal bovine serum, $1 \%$ L-glutamine, and $1 \%$ streptomycin/penicillin antibiotics, and PANC-1 cells in DMEM high glucose were supplemented with $10 \%$ fetal bovine serum, $1 \%$ Lglutamine, and $1 \%$ streptomycin/penicillin antibiotics. Culture media and supplements were purchased from Thermo Fisher Scientific (Waltham, MA). Eight-well Permanox Lab-Tek chamber slides were purchased from NUNC (cat. \#177445). ImmPRESS Reagent (antirabbit Ig) (cat. \#MP-7401) and ImmPACT DAB Peroxidase Substrate (cat. \#SK-4105) were purchased from Vector Laboratories (Burlingame, CA). A rabbit monoclonal antibody against DDR1 (D1G6) was purchased from Cell Signaling Technology (Danvers, MA), and a monoclonal antibody against $\beta$-actin was purchased from Sigma (St. Louis, MO). Mayer's hematoxylin (cat. \#HMM999) was purchased from Scytek and Crystal Mount Aqueous Mounting Medium (cat. \#C0612) from Sigma (S t.Louis, MO). Immunoblot analyses and cell immunostaining were performed to assess antibody specificity and sensibility.

For immunoblot analyses, cells were lysed in RIPA buffer $(50 \mathrm{mM}$ Tris- $\mathrm{HCl}, \mathrm{pH} 7.4,150 \mathrm{mM} \mathrm{NaCl}, 1 \% \mathrm{NP}-40,0.25 \%$ sodium deoxycholate and $1.0 \mathrm{mM}$ EDTA) supplemented with protease inhibitors on ice for $1 \mathrm{~h}$. The cell lysates were cleared by centrifugation at $14000 \mathrm{~g}$ at $4{ }^{\circ} \mathrm{C}$ for $15 \mathrm{~min}$, and protein concentration was determined using the BCA kit (Pierce). Amounts of $20-40 \mu \mathrm{g}$ of protein lysate were mixed with $1 \times$ reducing Laemmli SDS-sample buffer. After a brief centrifugation, the supernatants were boiled and resolved by reducing 7.5\% SDS-PAGE, followed by immunoblot analyses using anti-DDR1 antibody D1G6 or SC532. The blots were reprobed with antibodies against $\beta$-actin for loading control. For positive control of DDR1 immunoreactivity, we used a lysate of human prostate cancer PC 3 cells overexpressing DDR1b, which was generated in our laboratory.

For immunostaining, CFPAC- 1 or PANC-1 cells $\left(5 \times 10^{4} / 250 \mu \mathrm{L}\right.$ of complete medium) were seeded in 8-well chamber slides. At $24 \mathrm{~h}$ later, the media were removed and the cells were fixed with cold $\left(-20^{\circ} \mathrm{C}\right)$ methanol. The cells were then washed $(3 \times)$ with PBS and then incubated with $3 \% \mathrm{H}_{2} \mathrm{O}_{2}$ in PBS for 20 min at RT (RT) followed by two washes with PBS. The cells were incubated with $2.5 \%$ normal horse serum for $20 \mathrm{~min}$ at RT. The serum was removed and the cells were incubated with either in house raised DDR1 antibody (1:50) or control rabbit $\operatorname{IgG}(1: 50)$ diluted in PBS. After an overnight incubation at $4{ }^{\circ} \mathrm{C}$, 
the cells were washed with PBS and incubated with the ImmPRESS Reagent for $30 \mathrm{~min}$ at RT. Detection and visualization of antibody binding was assessed using ImmPACT DAB Peroxidase chromogenic substrate, according to the manufacturer instructions. The slides were counterstained with Mayer's hematoxylin for $5 \mathrm{~s}$, followed by differentiation with tap water for $1 \mathrm{~min}$, and finally covered with a thin layer of Crystal Mount Aqueous Mounting Medium. Stained cells were photographed using a Zeiss Axioplan 2 microscope (Zeiss, Gottingen, Germany) equipped with a software-controlled digital camera (Axiovision; Zeiss).

Human Renal Tissues. Human renal tissue, fixed in formaldehyde and embedded in paraffin, was selected from the files of the Service of Pathology, University Hospital Geneva. The institutional ethical committee board approved the clinical protocol (CEREH number 03-081). The research was performed according to the Helsinki's declaration principles.

Immunohistochemistry on Human Tissues. Immunohistochemistry on Alport patient tissue was performed as follows: after antigen heat retrieval, $3 \mu \mathrm{m}$ sections of the formaldehyde-fixed, paraffinembedded biopsy specimens were incubated with our specifically inhouse raised rabbit monoclonal anti-human DDR1 antibody at a 1:100 dilution $1 \mathrm{~h}$ at RT followed by an antirabbit antibody for $30 \mathrm{~min}$ (RT) and then liquid diaminobenzidine substrate-chromogen system (DakoCytomation, Glostrup, Denmark). Counterstaining was performed using Mayer hematoxylin. Stained sections were examined with a Zeiss microscope.

Mice and Animal Studies. All animal studies have been conducted in compliance with the US Department of Health and Human Services Guide for the Care and Use of Laboratory Animals and were approved by the Institutional Animal Care and Use Committee at the University of Miami (protocol number 15-226 NEW, approval date 14-Jan-2016). Col4a 3 KO mice were used as a model of AS (129-Col4a $3^{\text {tm1Dec }} / \mathrm{J}$, \#002908, Jackson Laboratories) and maintained as heterozygous colony. Four-week-old female and male Col4a $3 \mathrm{KO}\left(\mathrm{Col} 43^{-/-}\right)$and Col4a 3 wild-type $\left(\mathrm{Col} 4 \mathrm{a}^{+/+}\right)$mice were injected intraperitoneally with 2.45 (90 mg/kg bw, Roche) or vehicle on a daily basis. Four groups of four-week-old mice were utilized for functional studies and for assessment of fibrosis: $\mathrm{wt}+$ vehicle $(n=10)$, wt $+2.45(n=11)$, ko + vehicle $(n=11)$, and ko $+2.45(n=14)$. Body weight was determined weekly. Of those, a selected group of mice were utilized to obtain cell lysates for immunoprecipitation studies: $\mathrm{wt}+$ vehicle $(n=8), \mathrm{wt}+\mathbf{2 . 4 5}$ $(n=8)$, ko + vehicle $(n=6)$, and ko $+2.45(n=10)$.

Urine and Blood Analysis. Urine and blood were sampled weekly and analyzed for albumin, creatinine, and BUN. At 8 weeks of age, mice were sacrificed and kidney tissue, blood, and urine were collected for further analysis. Kidneys were harvested for further analysis as previously described. Blood samples were collected and analyzed for serum blood urea nitrogen (BUN) levels in the Comparative Laboratory Core Facility (University of Miami). Serum creatinine was determined by tandem mass spectrometry at the UAB-UCSD O'Brien Core Center (University of Alabama at Birmingham) as previously described. ${ }^{48,49}$ The urine albumin content was measured by ELISA (Bethyl Laboratories, TX). The urine creatinine content was assessed by an assay based on the Jaffe method (Stanbio Laboratory). Albumin/creatinine ratio (ACR) values were calculated and expressed as microgram albumin per milligram of creatinine.

Immunohistochemistry and Histology. For Picro Sirius Red staining, paraffin-embedded sections ( $4 \mu \mathrm{m}$ thick) were deparaffinized with xylene and a graded alcohol series. Sections were rinsed, stained for $1 \mathrm{~h}$, with Picro Sirius Red in saturated aqueous picric acid, and examined under a light microscope, and photomicrographs were taken. Histological images were visualized using a light microscope (Olympus BX 41, Tokyo, Japan) at $10 \times$ magnification and analyzed using Image J software. ${ }^{50}$ Cryosections $(4 \mu \mathrm{m})$ of kidneys from 8 week old wild type and Alport mice were subjected to immunohistochemical staining analysis. Antibodies used were specific for $\alpha$-smooth muscle actin (monoclonal 1A4 anti-mouse; Sigma-Aldrich, used at 1:500 dilution) and type I collagen (rabbit polyclonal; Abcam, used at 1:500 dilution). Histological images were visualized using a confocal immunofluor- escence microscopy (Leica, Germany) at $20 \times$ magnification and analyzed using ImageJ software.

Immunoprecipitation and Western Blots. Kidney tissues were homogenized in cell lysis buffer (Cell Signaling) containing Phosphatase Inhibitor Cocktail PhosStop (Roche Applied Sciences, Switzerland), $0.5 \mathrm{mM}$ dithiothreitol (DTT), Protease Inhibitor Cocktail Complete EDTA free (Roche Applied Sciences, Switzerland), and PMSF 0.1 M (Sigma, St Louis, MO). Homogenized tissues were centrifuged at $2000 \mathrm{~g}$ for $10 \mathrm{~min}$ at $4{ }^{\circ} \mathrm{C}$. Supernatants were collected, and protein concentration was estimated with BCA (dilution 1/20). Then $1.5 \mathrm{mg}$ of proteins were mixed with anti-human antibody DDR1 (R\&D) for $1 \mathrm{~h}$ at $4{ }^{\circ} \mathrm{C}$ with continuous agitation. The reaction mixtures were incubated with $50 \%$ slurry of protein G-sepharose (GE Healthcare, Sweden) at $4{ }^{\circ} \mathrm{C}$ for $2 \mathrm{~h}$ and centrifuged at $4000 \mathrm{rpm}$ for $30 \mathrm{~s}$. The pellets were resuspended in sample buffer solution NuPAGE $4 \mathrm{x}$ (Life Technologies) and NuPAGE sample reducing agent 10X containing $500 \mathrm{mM}$ DTT (Life Technologies), boiled for $5 \mathrm{~min}$ at 90 ${ }^{\circ} \mathrm{C}$, and centrifuged at $4000 \mathrm{rpm}, 4{ }^{\circ} \mathrm{C}$ for $30 \mathrm{~s}$. For Western blot, protein amounts of $15 \mu \mathrm{L}$ for phospho DDR1 detection and $5 \mu \mathrm{L}$ for DDR1 detection were loaded for SDS-PAGE on 4-20\% gels and transferred to nitrocellulose membranes. The duplicate blots were probed with rabbit anti-human C terminus DDR1 1:500 (C-20, Santa Cruz) at $4{ }^{\circ} \mathrm{C}$ overnight or rabbit anti-phospho DDR1 1:1000 (Y513, Cell Signaling) followed by corresponding secondary antibody. Detection was carried out using ECL Western blotting detection reagents (GE Healthcare, UK).

Statistical Analysis. Data are shown as mean \pm SD. Statistical analysis was performed with one-way ANOVA using GraphPrism software for Mac (version 5.0). When one-way ANOVA showed statistical significance, results were compared using Student's $t$ test. Results were considered statistically significant at $p<0.05$.

\section{ASSOCIATED CONTENT}

\section{S Supporting Information}

The Supporting Information is available free of charge on the ACS Publications website at DOI: 10.1021/acschembio. 8 b00866.

Additional cocrystal structures, compound activities, synthetic methods, and assay methods (PDF)

\section{AUTHOR INFORMATION}

\section{Corresponding Authors}

*E-mail: alexander_lee.satz@roche.com.

*E-mail: marco.prunotto@roche.com.

*E-mail: afornoni@med.miami.edu.

\section{ORCID}

\section{Alexander L. Satz: 0000-0003-1284-1977}

\section{Present Address}

$\boldsymbol{\Delta}_{\text {School of Pharmaceutical Sciences, University of Geneva, }}$ CMU, Rue Michel-Servet 1, 1211, Geneva, Switzerland

\section{Author Contributions}

${ }^{+}$H.R. and A.L.S. contributed equally to this work. H.R. designed the entire medicinal chemistry strategy aimed at and resulting in identification of compound 2.45; he also actively participated in the design and writing of the manuscript. A.S. oversaw DEL screening and follow-up efforts; he also actively participated in the design and writing of the manuscript. M.B. created the DDR1 and DDR2 cell lines used for in vitro phosphorylation assays. B.B. contributed to SAR development and suggested structural modifications of the new compounds. A.P. ran the second DDR1 screen. A.H. contributed scientific suggestion for the in vivo study. R.He. contributed scientific suggestion for the in vivo study. R.Ho. ran the in vitro binding assays and participated in DEL screening efforts. R.G. ran the pharmaco- 
kinetic studies for compound 2.45. S.H. performed surface plasmon resonance. B.Ko. contributed to the design of the new compounds by exploration of SAR and performed chemical synthesis of the new compounds. B.Ku. contributed the modeling of DDR1 and DDR2 inhibitor compounds; he also actively participated to design and writing of the manuscript. M.Ri. contributed to the design of the new compounds by generating and analyzing SAR and synthesized the new compounds. M.Ru. performed the crystallography and solved DDR1 and DDR2 kinase structures. F.W. ran the in vitro assays. J.M.D. ran the in vivo experiment in WT and Col4A3 $3^{-/-}$mice. J.J.K. ran the in vitro assays. J.V.S. ran the in vitro assays. S.U. ran the in situ hybridization for DDR1. S.M. ran the in vitro qRTPCR for the different fibrotic markers and performed DDR1 IHC. S. H. performed the in IHC and the original submitted ISH for DDR1. M.S. performed the compound/DDR1 cocrystallization. G.G. produced the in-house raised anti-human DDR1 antibody used for staining on Alport patient tissue. R.F. and R.D.F. characterized the specificity and sensitivity of the inhouse rabbit monoclonal anti-human DDR1 antibody. D.B. and B.G. contributed the purification of DDR1 and DDR2. C.F. contributed critical thinking and design for the in vivo experiment. A.F. contributed critical thinking and design for the in vivo experiment. She also actively participated to the design and writing of the manuscript. M.P. designed the biological experiments, analyzed the data, and wrote the manuscript.

\section{Notes}

The authors declare the following competing financial interest(s): F. W. was an employee of Hoffmann-La Roche Ltd. at the time those experiments were performed. J. M. D., J. K., J. V. S., and S. M. have no conflict of interest. C. F. and A. F. received research funding and consultancy from Hoffmann-La Roche Ltd. for the present work. A. F. is supported by National Institutes of Health Grants DK090316, DK117599, U01DK116101, U54DK083912, UM1DK100846, and 1UL1TR000460. J. K. is supported by the NIH Grant F32DK115109. R.F. and R.D.B. were supported by a grant from the Prostate Cancer Research Program of the Department of Defense, and RF was also supported by a grant from the Sky Foundation. All other authors are employees of Hoffmann-La Roche Ltd.

\section{ACKNOWLEDGMENTS}

We acknowledge for DDR1 construct design K. Hasegawa, T. Matuura, and S. Kadono for the fitst DDR1 protein crystallization. K.H, T.M., and S.K. were employees of Chugai Pharmaceutical Co. Ltd. at the time those experiments were performed. We also acknowledge T. Buelau, D. Schlatter, and J. Benz for DDR1 protein related activities. T. B., D. S., and J. B. are employees of Hoffmann-La Roche Ltd.

\section{REFERENCES}

(1) Wynn, T. A. (2008) Cellular and molecular mechanisms of fibrosis. J. Pathol. 214, 199-210.

(2) Rosenbloom, J., Castro, S. V., and Jimenez, S. A. (2010) Narrative review: fibrotic diseases: cellular and molecular mechanisms and novel therapies. Ann. Intern. Med. 152, 159-166.

(3) Rockey, D. C., Bell, P. D., and Hill, J. A. (2015) Fibrosis-A Common Pathway to Organ Injury and Failure. N. Engl. J. Med. 373, 95-96.
(4) Hinz, B., Phan, S. H., Thannickal, V. J., Prunotto, M., Desmoulière, A., Varga, J., De Wever, O., Mareel, M., and Gabbiani, G. (2012) Am. J. Pathol. 180, 1340-1355.

(5) Humphreys, B. D. (2018) Mechanisms of Renal Fibrosis. Annu. Rev. Physiol. 80, 309-326.

(6) Brenner, B. M., et al. (2001) Effects of losartan on renal and cardiovascular outcomes in patients with type 2 diabetes and nephropathy. N. Engl. J. Med. 345, 861-869.

(7) Pozzi, A., and Zent, R. (2013) Integrins in Kidney Disease. J. Am. Soc. Nephrol. 24, 1034-1039.

(8) Borza, C. M., and Pozzi, A. (2014) Discoidin domain receptors in disease. Matrix Biol. 34, 185-192.

(9) Prakoura, N., and Chatziantoniou, C. (2017) Periostin and Discoidin Domain Receptor 1: New Biomarkers or Targets for Therapy of Renal Disease. Front. Med. 4, 52.

(10) Francois, H., and Chatziantoniou, C. (2018) Renal fibrosis: Recent translational aspects. Matrix Biol. 68-69, 318-332.

(11) Vogel, W., Gish, G. D., Alves, F., and Pawson, T. (1997) The discoidin domain receptor tyrosine kinases are activated by collagen. Mol. Cell 1, 13-23.

(12) Fu, H. L., Valiathan, R. R., Arkwright, R., Sohail, A., Mihai, C., Kumarasiri, M., Mahasenan, K. V., Mobashery, S., Huang, P., Agarwal, G., and Fridman, R. (2013) Discoidin Domain Receptors: Unique Receptor Tyrosine Kinases in Collagen-mediated Signaling. J. Biol. Chem. 288, 7430-7437.

(13) Hahn, W. H., Suh, J. S., Cho, B. S., and Kim, S. D. (2010) Linkage and association study of discoidin domain receptor 1 as a novel susceptibility gene for childhood IgA nephropathy. Int. J. Mol. Med. 25, 785-791.

(14) Flamant, M., Placier, S., Rodenas, A., Curat, C. A., Vogel, W. F., Chatziantoniou, C., and Dussaule, J.-C. (2006) Discoidin Domain Receptor 1 Null Mice Are Protected against Hypertension-Induced Renal Disease. J. Am. Soc. Nephrol. 17, 3374-3381.

(15) Guerrot, D., Kerroch, M., Placier, S., Vandermeersch, S., Trivin, C., Mael-Ainin, M., Chatziantoniou, C., and Dussaule, J. C. (2011) Discoidin domain receptor 1 is a major mediator of inflammation and fibrosis in obstructive nephropathy. Am. J. Pathol. 179, 83-91.

(16) Kerroch, M., Alfieri, C., Dorison, A., Boffa, J.-J., Chatziantoniou, C., and Dussaule, J.-C. (2016) Protective effects of genetic inhibition of Discoidin Domain Receptor 1 in experimental renal disease. Sci. Rep. 6, 21262.

(17) Alfieri, C., Kavvadas, P., Simonini, P., Ikehata, M., Dussaule, J. C., Chadjichristos, C. E., Rastaldi, M. P., Messa, P., and Chatziantoniou, C. (2015) Discoidin domain receptor-1 and periostin: new players in chronic kidney disease. Nephrol., Dial., Transplant. 30, 1965-1971.

(18) Kerroch, M., Guerrot, D., Vandermeersch, S., Placier, S., Mesnard, L., Jouanneau, C., Rondeau, E., Ronco, P., Boffa, J. J., Chatziantoniou, C., and Dussaule, J. C. (2012) Genetic inhibition of discoidin domain receptor 1 protects mice against crescentic glomerulonephritis. FASEB J. 26, 4079-4091.

(19) Liu, L., Hussain, M., Luo, J., Duan, A., Chen, C., Tu, Z., and Zhang, J. (2017) Chem. Biol. Drug Des. 89, 420-427.

(20) Murray, C. W., Berdini, V., Buck, I. M., Carr, M. E., Cleasby, A., Coyle, J. E., Curry, J. E., Day, J. E., Day, P. J., Hearn, K., Iqbal, A., Lee, L. Y., Martins, V., Mortenson, P. N., Munck, J. M., Page, L. W., Patel, S., Roomans, S., Smith, K., Tamanini, E., and Saxty, G. (2015) FragmentBased Discovery of Potent and Selective DDR1/2 Inhibitors. ACS Med. Chem. Lett. 6, 798-803.

(21) Chen, C., Deng, J., Yu, X., Wu, F., Men, K., Yang, Q., Zhu, Y., Liu, $\mathrm{X}$., and Jiang, Q. (2016) Identification of novel inhibitors of DDR1 against idiopathic pulmonary fibrosis by integrative transcriptome meta-analysis, computational and experimental screening. Mol. BioSyst. $12,1540-1551$

(22) Han, K. C., Kim, S. Y., and Yang, E. G. (2012) Recent advances in designing substrate-competitive protein kinase inhibitors. Curr. Pharm. Des. 18,2875

(23) Olaso, E., Arteta, B., Benedicto, A., Crende, O., and Friedman, S. L. (2011) Loss of discoidin domain receptor 2 promotes hepatic fibrosis after chronic carbon tetrachloride through altered paracrine 
interactions between hepatic stellate cells and liver-associated macrophages. Am. J. Pathol. 179 (6), 2894-904.

(24) Miner, J., and Sanes, J. R. (1996) Molecular and functional defects in kidneys of mice lacking collagen alpha 3(IV): implications for Alport syndrome. J. Cell Biol. 135, 1403-1413.

(25) Rubel, D., Frese, J., Martin, M., Leibnitz, A., Girgert, R., Miosge, N., Eckes, B., Müller, G. A., and Gross, O. (2014) Collagen receptors integrin alpha2betal and discoidin domain receptor 1 regulate maturation of the glomerular basement membrane and loss of integrin alpha2beta1 delays kidney fibrosis in COL4A3 knockout mice. Matrix Biol. 34, 13-21.

(26) Gross, O., Girgert, R., Beirowski, B., Kretzler, M., Kang, H. G., Kruegel, J., Miosge, N., Busse, A. C., Segerer, S., Vogel, W. F., Müller, G. A., and Weber, M. (2010) Loss of collagen-receptor DDR1 delays renal fibrosis in hereditary type IV collagen disease. Matrix Biol. 29, 346-356.

(27) Eidam, O., and Satz, A. L. (2016) Analysis of the productivity of DNA encoded libraries. MedChem Comm 7, 1323-1331.

(28) Satz, A. L. (2015) DNA Encoded Library Selections and Insights Provided by Computational Simulations. ACS Chem. Biol. 10, $2237-$ 2245.

(29) Brown, D. G., and Boström, J. (2016) Analysis of Past and Present Synthetic Methodologies on Medicinal Chemistry: Where Have All the New Reactions Gone? J. Med. Chem. 59, 4443-4458.

(30) Racusen, L. C., Monteil, Sgrignoli, A., Lucskay, M., Marouillat, S., Rhim, J. G. S., and Morin, J.-P. (1997) Cell lines with extended in vitro growth potential from human renal proximal tubule: Characterization, response to inducers, and comparison with established cell lines. J. Lab. Clin. Med. 129, 318-329.

(31) Moll, S., Yasui, Y., Abed, H., Murata, T., Shimada, H., Maeda, A., Fukushima, N., Kanamori, M., Uhles, S., Badi, L., Cagarelli, T., Formentini, I., Drawnel, F., Georges, G., Bergauer, T., Gasser, R., Bonfil, D., Fridman, R., Richter, H., Funk, J., Moeller, M. J., Chatziantoniou, C., and Prunotto, M. (2018) Selective pharmacological inhibition of DDR1 prevents experimentally-induced glomerulonephritis in prevention and therapeutic regime. J. Transl. Med. 16, 148.

(32) Suleiman, H., Zhang, L., Roth, R., Heuser, J. E., Miner, J. H., Shaw, A. S., and Dani, A. (2013) Nanoscale protein architecture of the kidney glomerular basement membrane. eLife 2, e01149.

(33) Li, Y., Lu, X., Ren, X., and Ding, K. (2015) Small molecule discoidin domain receptor kinase inhibitors and potential medical applications. J. Med. Chem. 58, 3287-3301.

(34) Kim, H. G., Tan, L., Weisberg, E. L., Liu, F., Canning, P., Choi, H. G., Ezell, S. A., Wu, H., Zhao, Z., Wang, J., Mandinova, A., Griffin, J. D., Bullock, A. N., Liu, Q., Lee, S. W., and Gray, N. S. (2013) Discovery of a potent and selective DDR1 receptor tyrosine kinase inhibitor. ACS Chem. Biol. 8, 2145-2150.

(35) Day, E., Waters, B., Spiegel, K., Alnadaf, T., Manley, P. W., Buchdunger, E., Walker, C., and Jarai, G. (2008) Inhibition of collageninduced discoidin domain receptor 1 and 2 activation by imatinib, nilotinib and dasatinib. Eur. J. Pharmacol. 599, 44-53.

(36) Fernández-Montalván, A. E., Berger, M., Kuropka, B., Koo, S. J., Badock, V., Weiske, J., Puetter, V., Holton, S. J., Stöckigt, D., Ter Laak, A., Centrella, P. A., Clark, M. A., Dumelin, C. E., Sigel, E. A., Soutter, H. H., Troast, D. M., Zhang, Y., Cuozzo, J. W., Keefe, A. D., Roche, D., Rodeschini, V., Chaikuad, A., Díaz-Sáez, L., Bennett, J. M., Fedorov, O., Huber, K. V. M., Hübner, J., Weinmann, H., Hartung, I. V., and Gorjánácz, M. (2017) Isoform-Selective ATAD2 Chemical Probe with Novel Chemical Structure and Unusual Mode of Action. ACS Chem. Biol. 12, 2730-2736.

(37) Concha, N., Huang, J., Bai, X., Benowitz, A., Brady, P., Grady, L. C., Kryn, L. H., Holmes, D., Ingraham, K., Jin, Q., Pothier Kaushansky, L., McCloskey, L., Messer, J. A., O’Keefe, H., Patel, A., Satz, A. L., Sinnamon, R. H., Schneck, J., Skinner, S. R., Summerfield, J., Taylor, A., Taylor, J. D., Evindar, G., and Stavenger, R. A. (2016) Discovery and Characterization of a Class of Pyrazole Inhibitors of Bacterial Undecaprenyl Pyrophosphate Synthase. J. Med. Chem. 59, 7299-7304. (38) Satz, A. L., Hochstrasser, R., and Petersen, A. C. (2017) Analysis of Current DNA Encoded Library Screening Data Indicates Higher
False Negative Rates for Numerically Larger Libraries. ACS Comb. Sci. 19, 234-238.

(39) Goodnow, R. A., Jr., Dumelin, C. E., and Keefe, A. D. (2017) DNA-encoded chemistry: enabling the deeper sampling of chemical space. Nat. Rev. Drug Discovery 16, 131-147.

(40) Cuozzo, J. W., Centrella, P. A., Gikunju, D., Habeshian, S., Hupp, C. D., Keefe, A. D., Sigel, E. A., Soutter, H. H., Thomson, H. A., Zhang, Y., and Clark, M. A. (2017) Discovery of a Potent BTK Inhibitor with a Novel Binding Mode by Using Parallel Selections with a DNA-Encoded Chemical Library. ChemBioChem 18, 864-871.

(41) Franzini, R. M., Nauer, A., Scheuermann, J., and Neri, D. (2015) Interrogating target-specificity by parallel screening of a DNA-encoded chemical library against closely related proteins. Chem. Commun. 51, 8014-8016.

(42) Grgic, I., Campanholle, G., Bijol, V., Wang, C., Sabbisetti, V. S., Ichimura, T., Humphreys, B. D., and Bonventre, J. V. (2012) Targeted proximal tubule injury triggers interstitial fibrosis and glomerulosclerosis. Kidney Int. 82, 172-183.

(43) Koesters, R., Kaissling, B., Lehir, M., Picard, N., Theilig, F., Gebhardt, R., Glick, A. B., Hähnel, B., Hosser, H., Gröne, H. J., and Kriz, W. (2010) Tubular overexpression of transforming growth factor-beta 1 induces autophagy and fibrosis but not mesenchymal transition of renal epithelial cells. Am. J. Pathol. 177, 632-643.

(44) Rubel, R. G. D., Mueller, G. A., and Gross, O. Paper presented at the ASN Kidney Week 2017, New Orleans, LA, USA, 2017.

(45) Kashtan, C. E., Ding, J., Gregory, M., Gross, O., Heidet, L., Knebelmann, B., Rheault, M., and Licht, C. (2013) Clinical practice recommendations for the treatment of Alport syndrome: a statement of the Alport Syndrome Research Collaborative. Pediatr. Nephrol. 28, 511 .

(46) Gross, O., Friede, T., Hilgers, R., Görlitz, A., Gavénis, K., Ahmed, R, and Dürr, U. (2012) Safety and Efficacy of the ACE-Inhibitor Ramipril in Alport Syndrome: The Double-Blind, Randomized, Placebo-Controlled, Multicenter Phase III EARLY PRO-TECT Alport Trial in Pediatric Patients. ISRN Pediatr. 2012, 436046.

(47) Ortiz, A., Sanchez-Niño, M. D., Izquierdo, M. C., Martin-Cleary, C., Garcia-Bermejo, L., Moreno, J. A., Ruiz-Ortega, M., Draibe, J., Cruzado, J. M., Garcia-Gonzalez, M. A., Lopez-Novoa, J. M., Soler, M. J., and Sanz, A. B. (2015) Translational value of animal models of kidney failure. Eur. J. Pharmacol. 759, 205-220.

(48) Zhong, J., Yang, H. C., and Fogo, A. B. (2017) A perspective on chronic kidney disease progression. Am. J. Physiol. 312, F375-F384.

(49) Takahashi, N., Boysen, G., Li, F., Li, Y., and Swenberg, J. A. (2007) Tandem mass spectrometry measurements of creatinine in mouse plasma and urine for determining glomerular filtration rate. Kidney Int. 71, 266-271.

(50) Montes, G. S. (1996) Structural biology of the fibres of the collagenous and elastic systems. Cell. Biol. Int. 20, 15-27. 